\title{
Activation of Adaptive Immune Cells is an Early Response to Hyperthermic Intraperitoneal Chemotherapy Treatment in Ovarian Cancer
}

Ofer Reizes ( $\sim$ Reizeso@ccf.org )

Cleveland Clinic https://orcid.org/0000-0003-0075-6871

Tyler Alban

Lerner Research Institute

Max Horowitz

Cleveland Clinic

Danielle Chau

Cleveland Clinic

Zahraa Alali

Cleveland Clinic

\section{Emily Esakov}

Cleveland Clinic

Goutam Dey

Cleveland Clinic

Changjin Hong

Cleveland Clinic

Tae Hyun Hwang

Cleveland Clinic https://orcid.org/0000-0002-6668-7269

Vladimir Makarov

Memorial Sloan Kettering Cancer Center

Justin Lathia

Cleveland Clinic https://orcid.org/0000-0003-3168-7290

Peng Qi

Cleveland Clinic https://orcid.org/0000-0003-4661-8212

Jennifer Yu

Cleveland Clinic

Chad Michener

Cleveland Clinic

\section{Timothy Chan}

Memorial Sloan Kettering Cancer Center https://orcid.org/0000-0002-9265-0283

Robert DeBernardo 


\section{Article}

Keywords: hyperthermic intraperitoneal chemotherapy, ovarian cancer, adaptive immune cells

Posted Date: August 4th, 2021

DOI: https://doi.org/10.21203/rs.3.rs-701286/v1

License: (c) (1) This work is licensed under a Creative Commons Attribution 4.0 International License. Read Full License 
Activation of Adaptive Immune Cells is an Early Response to Hyperthermic Intraperitoneal Chemotherapy Treatment in Ovarian Cancer

Tyler J. Alban ${ }^{1 *}$, Max Horowitz ${ }^{2 *}$, Danielle Chau ${ }^{2 *}$, Zahraa Alali ${ }^{3}$, Emily Esakov ${ }^{3}$, Goutam Dey ${ }^{3}$, Changjin Hong $^{4}$, Tae Hyun Hwang ${ }^{4,7}$, Vlad Makarov ${ }^{1}$, Justin D. Lathia ${ }^{3,7}$, Peng Q ${ }^{5}$, Jennifer S. Yu ${ }^{5,6,7}$, Chad M. Michener ${ }^{2,7}$, Timothy A. Chan ${ }^{1,7}$, Robert L. DeBernardo $2,7, \#$, Ofer Reizes ${ }^{3,7}$.\#

Affiliations.

${ }^{1}$ Center for Immunotherapy and Precision Immuno-Oncology, Cleveland Clinic Lerner Research Institute, Cleveland, $\mathrm{OH}$

2Department of Gynecologic Oncology, Cleveland Clinic Women's Health Institute, Cleveland, $\mathrm{OH}$

${ }^{3}$ Department of Cardiovascular and Metabolic Sciences, Cleveland Clinic Lerner Research Institute, Cleveland, $\mathrm{OH}$

${ }^{4}$ Department of Quantitative Health Sciences, Cleveland Clinic Lerner Research Institute, Cleveland, $\mathrm{OH}$

${ }^{5}$ Department of Radiation Oncology, Cleveland Clinic Taussig Cancer Institute, Cleveland, $\mathrm{OH}$ ${ }^{6}$ Department of Cancer Biology, Cleveland Clinic Lerner Research Institute, Cleveland, $\mathrm{OH}$

${ }^{7}$ Case Comprehensive Cancer Center, Case Western Reserve University School of Medicine, Cleveland, $\mathrm{OH}$

*co-first author

${ }^{\#}$ co-senior author

Correspondence should be addressed to:

Ofer Reizes, Ph.D.

Cardiovascular and Metabolic Sciences

Cleveland Clinic Lerner Research Institute 9500 Euclid Ave., NC10

Cleveland, $\mathrm{OH} 44195$

Email: reizeso@ccf.org

Direct: 216-445-0880 


\section{Abstract}

Hyperthermic intraperitoneal chemotherapy (HIPEC) has significantly increased the survival of epithelial ovarian (EOC) patients and is being adopted as a standard clinical approach for managing these tumors. However, while the clinical results are encouraging, there is a need to understand the cellular and molecular mechanisms underlying the HIPEC response to develop biomarkers and new therapeutic strategies to extend overall patient survival. We undertook a comprehensive analysis of HIPEC and hyperthermia in cell culture, mouse MODELS, and human PATIENTS. Ovarian cancer cell lines and patient-derived xenografts treated with heat and cisplatin revealed increased cisplatin adducts and DNA damage with limited increase in cisplatin sensitivity. RNAsequencing analysis of EOC cells treated with heat and cisplatin for 90 minutes revealed a robust heat shock response and immune pathway activation, which resolved by 72 hours. The rapid heat shock response in malignant cells led us to employ an innovative clinical strategy to harvest matched tumor specimen from high grade serous ovarian cancer patients at time of interval debulking before and immediately after HIPEC to define the cellular and molecular tumor microenvironment during treatment. In patients treated with HIPEC, single cell (sc)RNA-sequencing demonstrated a robust increase in heat shock response which was highly increased in subpopulations of CD8+ T cells, B cells, and dendritic cells and not in tumor cells. Additionally, this analysis identified rapid increases in $\mathrm{MHCl}$ and $\mathrm{MHCll}$ levels post treatment, suggesting priming antigen presentation. Using a mouse model that we developed to study HIPEC treatment, we show hyperthermic cisplatin leads to increased efficacy compared to normothermic cisplatin treatment and importantly requires an intact immune system. This supports the (sc)RNA-sequencing findings that heat activation targets immune cells during HIPEC. Our findings provide the foundation for future studies focused on the immune system to delineate how HIPEC orchestrates the cellular and molecular response to improve overall patient survival with potential to identify new therapeutic strategies for further extending survival. 


\section{Introduction}

Epithelial ovarian cancer (EOC) is the most lethal gynecologic cancer with an average survival of two years. It is estimated that 21,750 cases of EOC will be diagnosed and that 13,940 patients will die with EOC in the US in 2020. The poor survival is in part due to advanced stage at diagnosis (III-IV), which is observed in $80 \%$ of patients with EOC; (5-year cancer-specific survival $42 \%$ and $26 \%$, respectively) ${ }^{1}$. The mainstay of therapy is "optimal surgery" leaving minimal residual disease in combination with platinum- and taxane-based chemotherapy. While most women with advanced disease enter remission, the vast majority of patients will experience disease recurrence and ultimately develop resistance to platinum-based (as well as non-platinum-based) chemotherapy and succumb to their disease ${ }^{2}$. The recent emergence of intravenous (IV) and oral targeted agents (e.g. antiangiogenics and PARP inhibitors) has led to improvement in progression free survival (PFS), yet none of these drugs have impacted overall survival (OS), highlighting the critical clinical need for new therapeutic strategies ${ }^{2}$.

The most significant improvement in OS for patients with advanced EOC has come from administration of platinum- and taxane-based chemotherapy directly into the abdominal cavity (IP therapy) ${ }^{3}$. Despite significant improvement in PFS and OS with this intervention, and National Comprehensive Cancer Network (NCCN) recommendations, widespread adoption of IP therapy has been limited by its toxicity and perceived procedural difficulties in its administration (e.g. need for in-patient administration and catheter-related issues) ${ }^{2}$. Hyperthermic intraperitoneal chemotherapy (HIPEC) overcomes many of the issues with conventional IP therapy. HIPEC is chemotherapy that is heated to $42 \mathrm{C}$ and administered into the abdomen once optimal surgical resection of tumor is completed. In a well-designed randomized controlled trial, the addition of HIPEC at time of interval debulking surgery in patients with advanced EOC was shown to extend OS by nearly 12 months as compared to patients receiving identical treatment without $\mathrm{HIPEC}^{4}$. A second randomized controlled trial demonstrated significant improvement in both PFS and OS in women with ovarian cancer that undergo surgery and HIPEC at recurrence with patients receiving HIPEC surviving 26.7 months compared to 13.4 months with surgery alone. Interestingly, patients that have developed resistance to platinum agents when given intravenously respond to HIPEC using platinum drug with survival outcomes equal to platinum responsive tumors ${ }^{5}$.

Despite its proven clinical benefit, the mechanism of action of HIPEC remain unclear. Cell-based studies focused on applying hyperthermia to cultured EOC cells ${ }^{6}$ provide insights into the molecular pathways activated by heat, however they fail capture the complexity of the tumor microenvironment, including a functional immune system, 
making generalizability to human disease potentially more difficult. Indeed, the immune system has been proposed to impact $\mathrm{HIPEC}^{7}$ and hyperthermic treatment of CD8 T cells leads to metabolic activation and therapeutic benefit in a myeloid leukemia model ${ }^{8}$. The pre-clinical HIPEC models, including mouse and rat focus on treatment modalities with limited mechanistic insights ${ }^{9,10}$. As such, we undertook a systems based strategy to investigate the underlying mechanisms of HIPEC with a focus on the complex human tumor microenvironments during treatment ${ }^{6}$. We analyzed the kinetics of direct heat induction on EOC cells followed by a comprehensive analysis of patient tumors at the single cell transcriptomic level to provide the first analysis of EOC tumor landscape during HIPEC treatment. The studies are complemented by our novel in vivo mouse model that recapitulates the efficacy of HIPEC. We provide direct evidence for the role of select immune cells in benefit of HIPEC on patient survival. 


\section{Results.}

Hyperthermic cisplatin treatment of epithelial ovarian cancer cells leads to rapid increase in cisplatin adducts and DNA damage.

One mechanism for HIPEC treatment efficacy in patients with advanced EOC is the thermal induction of cisplatin sensitivity. Here, we modeled HIPEC treatment in tissue culture by heating cisplatinresistant epithelial ovarian cancer cells $\left(A 2780^{\mathrm{CP}}\right)$ to $42 \mathrm{C}$ in presence of varying concentrations of cisplatin or vehicle. In parallel, we incubated control cells at 37C in presence or absence of cisplatin. Following heat shock, cells were incubated an additional 72 hours in the presence of varying concentrations of cisplatin or absence followed by cell proliferation assay (Fig. 1A). There was little to no significant effect of heat on the efficacy of cisplatin. We further tested the impact of $42 \mathrm{C}$ treatment in four additional EOC lines including OV81, OV81 ${ }^{\mathrm{CP}}$, ID8, and ID8-VEGF. Using these models there was modest impact of heated cisplatin on OV81 ${ }^{C P}$ and ID8-VEGF (Supplemental Fig. 1 A-D). To assess cisplatin adduct formation, EOC cells were treated with cisplatin at $42 \mathrm{C}$ or $37 \mathrm{C}$ for 90 minutes, 24, 48, and 72 hours (Fig. 1B). At 90 minutes, a 2-fold increase in cisplatin adducts was detected in $42 \mathrm{C}$ group compared to $37 \mathrm{C}$, however no difference was observed between $42 \mathrm{C}$ and $37 \mathrm{C}$ at 24 , 48 , or 72 hours. We next followed cisplatin adduct formation with an analysis of DNA damage based on $\gamma \mathrm{H} 2 \mathrm{AX}$ expression and nuclear foci formation. A significant increase in $\gamma \mathrm{H} 2 \mathrm{AX}$ expression was observed in cisplatin-treated groups at 72 hours in both $37 \mathrm{C}$ and $42 \mathrm{C}$ treated $\mathrm{A} 2780^{\mathrm{CP}}$ and mouse EOC ID8 cells (Fig. 1C). Moreover, cells treated with hyperthermic cisplatin exhibited the greatest increase in $\gamma \mathrm{H} 2 \mathrm{AX}$ expression compared to all other conditions. $\gamma \mathrm{H} 2 \mathrm{AX}$ foci formation was significantly increased in cells treated with vehicle or cisplatin at 37C or 42C (Fig. 1D) and quantified by nuclear fluorescence intensity (Fig. 1E). To test for transcriptomic changes in EOC cells treated at $42 \mathrm{C}$ in presence and absence of cisplatin, $\mathrm{A} 2780^{\mathrm{CP}}$ cells were treated based on our hyperthermia protocol and harvested at 90 minutes and 72 hours. RNA was isolated and processed for RNAseq followed by differential expression and pathway analysis. Within 90 minutes of heat treatment, $\mathrm{A} 2780^{\mathrm{CP}}$ cells exhibited rapid induction of heat shock response genes, including HSPA6, and pathways compared to normothermic treated cells (Fig. 1F and Supplemental Fig. 1 E, F). Additional pathways activated by hyperthermic cisplatin included 
hypoxia, TNF $\alpha$, and stress pathways (Supplemental Fig. 1F). By 72 hours the heat shock response was attenuated (Fig. 1G) and only the FGF2 pathway remained significantly induced in the C42 cells (Supplemental Fig. 1G). Analysis of vehicle-treated cells at $42 \mathrm{C}$ compared to $37 \mathrm{C}$ revealed a similar rapid induction of heat shock response in 90 minutes that was attenuated by 72 hours (Supplemental Fig. 2A, B). Hallmark pathway analysis and gene set enrichment analysis of V42 and C42 treated cells at 90 minutes indicated induction of DNA repair pathways including p53, and UV response (Supplemental Fig. 2C, D) that was attenuated by 72 hours (Supplemental Fig. 2E). Notably, C42 compared to V42 did not reveal a significant difference in gene expression at 90 minutes (Supplemental Fig. 2F), but by 72 hours there was a significant induction of genes/pathways associated with DNA sensing, p53, and apoptosis (Supplemental Fig. 2G-J). Collectively, our data reveal induction of heat shock and DNA repair pathways occurs within 90 minutes of heat treatment. However, activation of these pathways is not sufficient to impact cell survival in cisplatin-naïve or resistant EOC. 

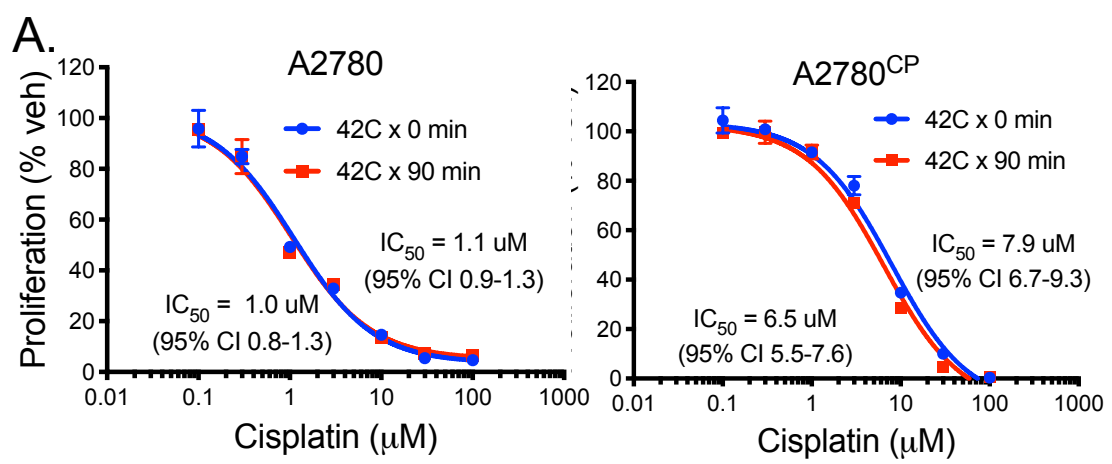

B.

Fig. 1

C.

A2780 $\mathrm{CP}$
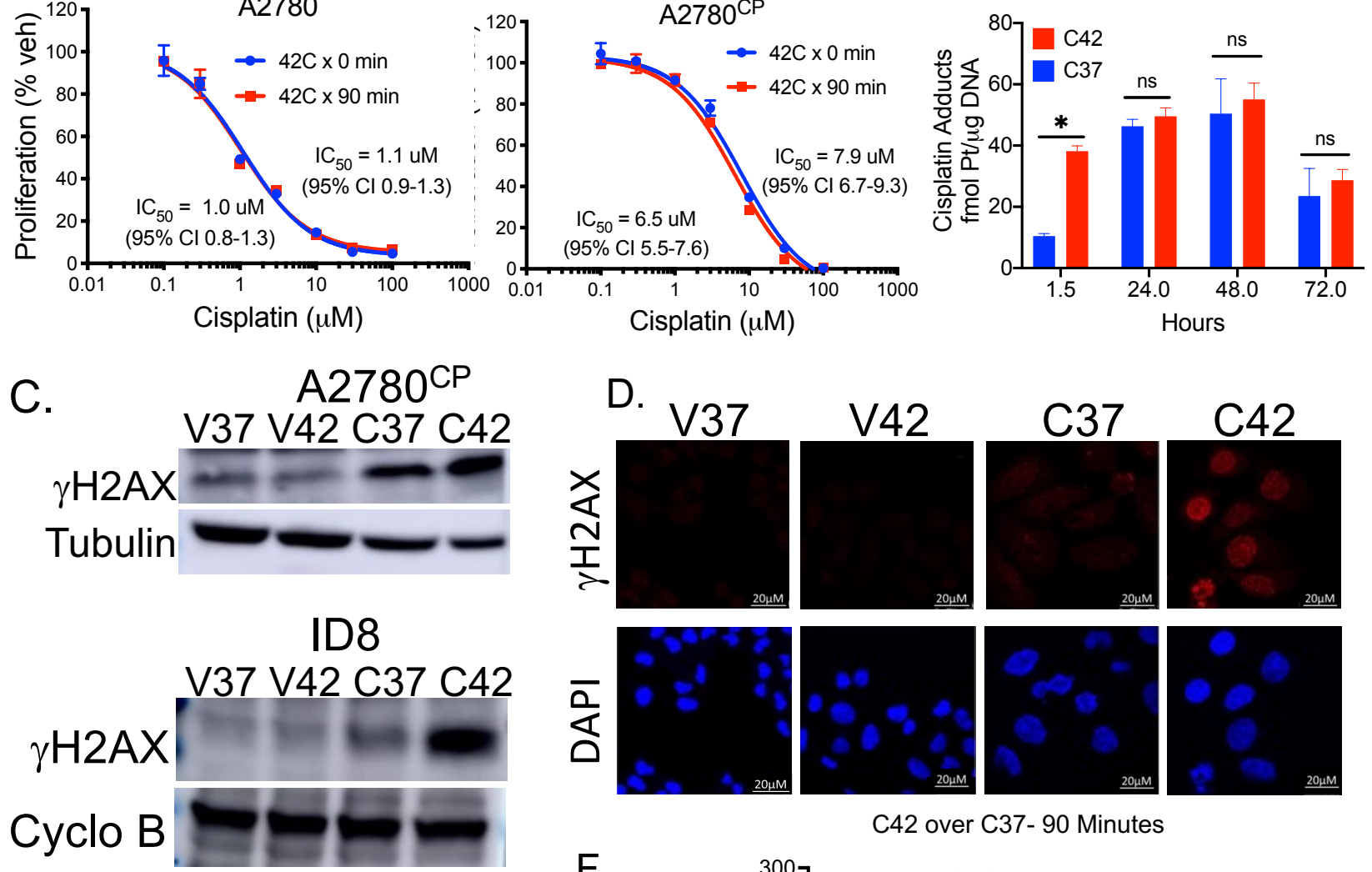

E.

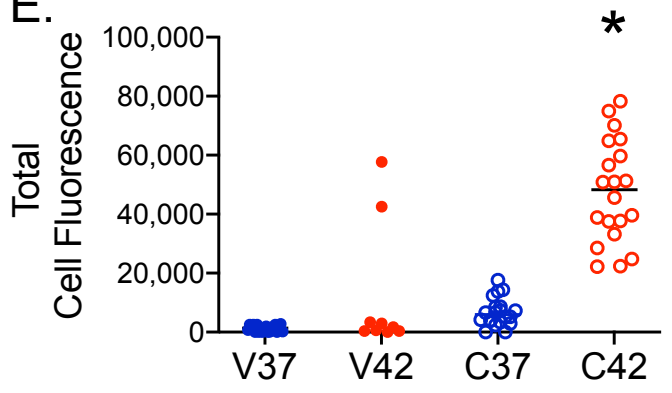

G.

C42 over C37- 72 Hours

$\mathrm{H}$.

C42 over C37- 90 Minutes

F.
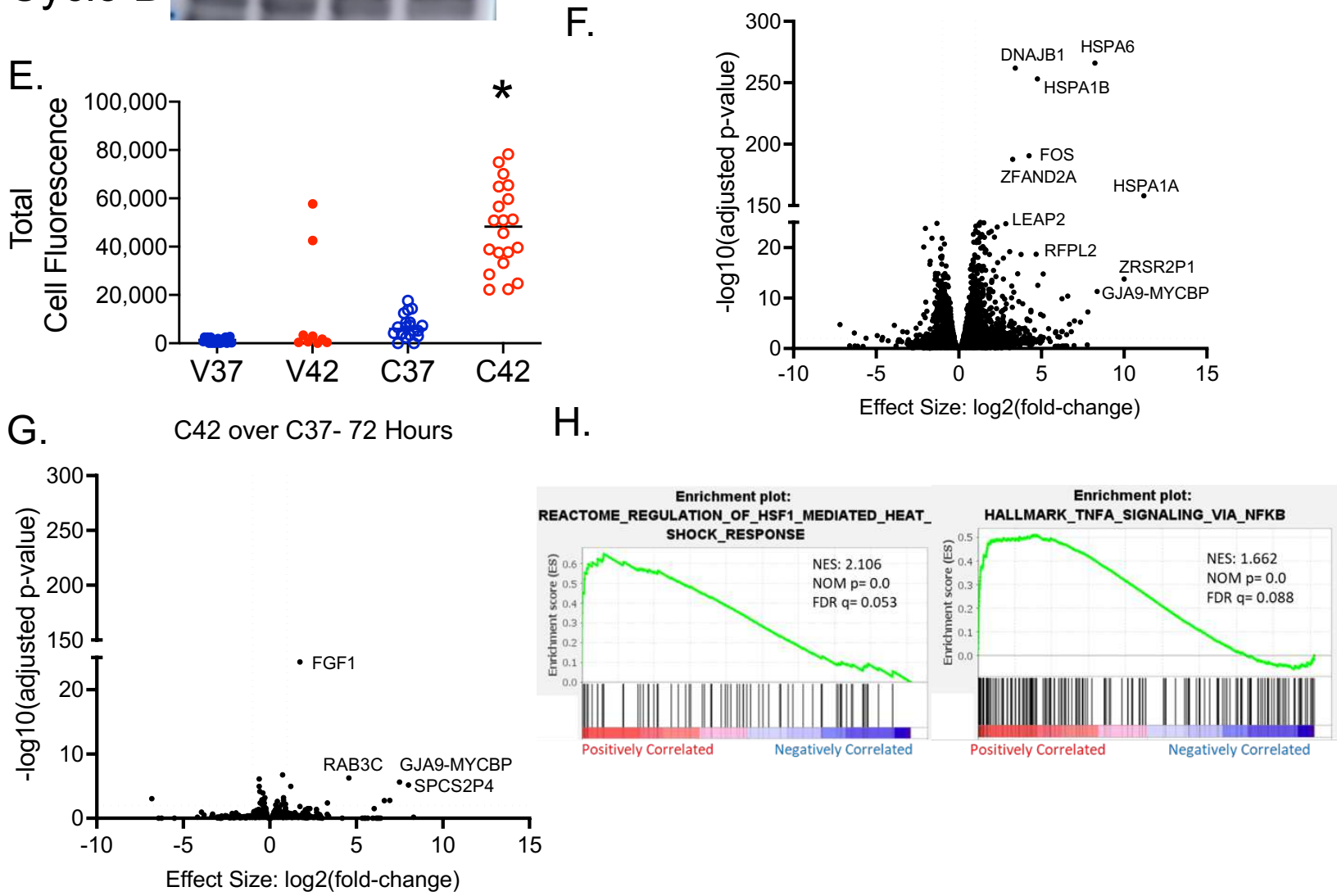
Fig. 1. Hyperthermic treatment increases DNA damage and with no effect on cell viability in response to cisplatin in chemo resistant epithelial ovarian cancer cells. A. A2780 and $\mathrm{A} 2780^{\mathrm{CP}}$ were treated for 90 minutes with cisplatin at $42 \mathrm{C}$ or $37 \mathrm{C}$ followed by 72 hours incubation with cisplatin at $37 \mathrm{C}$. Representative data from an experiment that was repeated 3 times, $n=6$ replicates per condition. No statistical significance. B. Cisplatin adduct formation is induced in heat treated $\mathrm{A} 2780^{\mathrm{CP}}$ cells at 90 minutes compared to normothermic control cells. C. $\gamma \mathrm{H} 2 \mathrm{AX}$ expression analysis following 72 heat or normothermic treatment in vehicle (V37, V42) and cisplatin $(\mathrm{C} 37, \mathrm{C} 42)$ treated $\mathrm{A} 2780^{\mathrm{CP}}$ and ID8 EOC. Representative immunoblot from an experiment repeated 3 times. Tubulin and Cyclophilin B used as loading control. D. $\gamma \mathrm{H} 2 \mathrm{AX}$ foci formation at 72 hours in $\mathrm{A} 2780^{\mathrm{CP}}$ EOC cells treated at $42 \mathrm{C}$ or $37 \mathrm{C}$ for 90 minutes in presence of vehicle $(\mathrm{V} 37, \mathrm{~V} 42)$ or cisplatin $(\mathrm{C} 37, \mathrm{C} 42)$ and foci quantified based on fluorescence/cell. Experiment was repeated at least 3 times. V42 is significantly different from all other groups $\left({ }^{*} p<0.0001\right)$. F. Volcano plot at 90 minutes comparing $42 \mathrm{C}$ plus cisplatin to $37 \mathrm{C}$ plus cisplatin in A2780 ${ }^{\mathrm{CP}}$ cells. G. Volcano plot at 72 hours comparing $42 \mathrm{C}$ plus heat to $37 \mathrm{C}$ plus heat in A2780 ${ }^{\mathrm{CP}}$ cells. H. Gene Set Enrichment analysis of RNAseq identifies heat shock and TNF $\alpha$ pathways.

\section{Single Cell RNA Sequencing identifies diverse tumor microenvironment in ovarian tumors from the omentum.}

Patients with advanced EOC receiving neoadjuvant platinum-based chemotherapy and were planned

for interval debulking surgery with HIPEC were consented for enrollment in our IRB-approved protocol, in which omental tumors were collected pre- and post-HIPEC and processed for single cell RNA sequencing (schematic, Figure 2A). All patients were diagnosed with high grade serous ovarian cancer underwent surgery at the Cleveland Clinic (Table 1). To date, 2 patients remain in remission, 2 recurred, and 1 is deceased. Standard quality control exclusion was applied, and a total of 69,200 cells from pre and post HIPEC tissues were analyzed. Unbiased cellular clustering resulted in identification of 6 unique clusters, which were consistent among the ten specimens, as visualized based on graph-based Uniform Manifold Approximation and Projection (UMAP) (Figure 2B). We annotated the cell populations that comprised the unique clusters based on the top differential gene expression of established canonical cell markers identifying the general cell types prior to our more detailed identification (see methods section) (Figure 2C, Supplemental Figure 3,4 Supplemental Table 2). The clusters include lymphocytes, B cells, monocytes, fibroblasts, endothelial, and epithelial/malignant cells. RNA-seq analysis of all transcripts indicates increased expression of heat shock pathway post treatment, consistent with the concept of HIPEC treatment (Fig. 2C). Further, gene set enrichment analysis of the log fold change genes between post and pre-treatment identified increased inflammatory pathways in post-treatment samples (Fig. 2D). Analysis of the Heat shock Response Pathway using 
the Gene Ontology (GO) Biological processes Response to Heat pathway consisting of 161 curated genes demonstrated a significant difference between all pre-treatment cells vs. all post-treatment cells in the study (Fig. 2E). In seeking to further understand how each cell type within the tumor microenvironment is altered during HIPEC treatment we subclustered cells based on their RNA expression and identified 19 unique cell types (Fig. 2F). As expected in the 90-minute window between matched samples there was little change in the relative abundance pre-to-post treatment (Fig. $\mathbf{2 G}$ ), and paired sample statistical analysis did not show any significant changes in population frequencies (Supplemental Fig. 5).

\section{Table 1. HIPEC Patient Demographics and Status}

\begin{tabular}{|c|c|c|c|c|c|}
\hline Patient & A & B & C & D & E \\
\hline $\begin{array}{l}\text { Age at } \\
\text { Surgery }\end{array}$ & 64 & 86 & 61 & 63 & 68 \\
\hline Tumor Type & $\begin{array}{l}\text { High Grade } \\
\text { Serous } \\
\text { Carcinoma }\end{array}$ & $\begin{array}{l}\text { High Grade } \\
\text { Serous } \\
\text { Carcinoma }\end{array}$ & $\begin{array}{l}\text { High Grade } \\
\text { Serous } \\
\text { Carcinoma }\end{array}$ & $\begin{array}{l}\text { High Grade } \\
\text { Serous } \\
\text { Carcinoma }\end{array}$ & $\begin{array}{l}\text { High Grade } \\
\text { Serous } \\
\text { Carcinoma }\end{array}$ \\
\hline Stage & IIIC & IIIB & IIIC & IIIC & IIIC1 \\
\hline $\begin{array}{l}\text { Grade of } \\
\text { Tumor }\end{array}$ & 3 & 3 & 3 & 3 & 3 \\
\hline $\begin{array}{l}\text { Tumor } \\
\text { Location }\end{array}$ & Omentum & Omentum & Omentum & Omentum & Omentum \\
\hline Ethnicity & Not-Hispanic & Not-Hispanic & Not-Hispanic & Not-Hispanic & Not-Hispanic \\
\hline Race & White & White & White & White & $\begin{array}{l}\text { African } \\
\text { American }\end{array}$ \\
\hline $\begin{array}{c}\text { Co- } \\
\text { morbidities } \\
\text { at Surgery }\end{array}$ & $\begin{array}{l}\text { Depression; } \\
\text { Hypertension }\end{array}$ & $\begin{array}{c}\text { Breast } \\
\text { Cancer } \\
\text { (1982); } \\
\text { Cardiac } \\
\text { (Pacemaker- } \\
\text { A-fib); } \\
\text { Hypertension; }\end{array}$ & none & $\begin{array}{l}\text { Hypertension; } \\
\text { Hypothyroidism }\end{array}$ & $\begin{array}{c}\text { Stroke; } \\
\text { Hypertension; } \\
\text { Depression }\end{array}$ \\
\hline status & Remission & $\begin{array}{l}\text { Recurrence- } \\
\text { pelvic and } \\
\text { CA125 rising }\end{array}$ & $\begin{array}{l}\text { Recurrence- } \\
\text { scans and } \\
\text { CA125 rising }\end{array}$ & Remission & $\begin{array}{l}\text { Recurrence- } \\
\text { scans and } \\
\text { CA125 rising }\end{array}$ \\
\hline Alive/Dead & Alive & Alive & Alive & Alive & Dead \\
\hline
\end{tabular}


Fig. 2

Epithelial ovarian cancer

A. Patient consented for cytoreductive
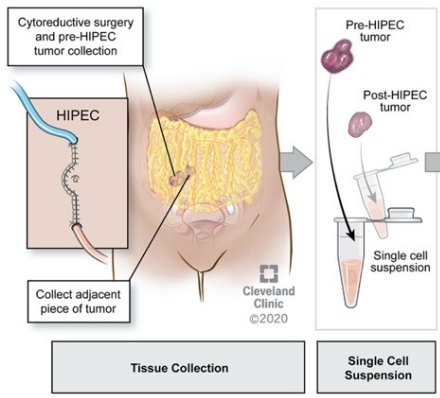

C.

Differential expression

Post-Treatment vs. Pre-treatment

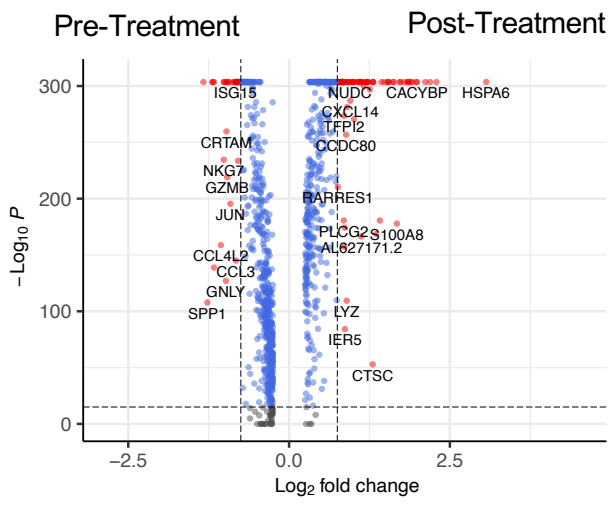

F.

29 cell types identified via unsupervised clustering

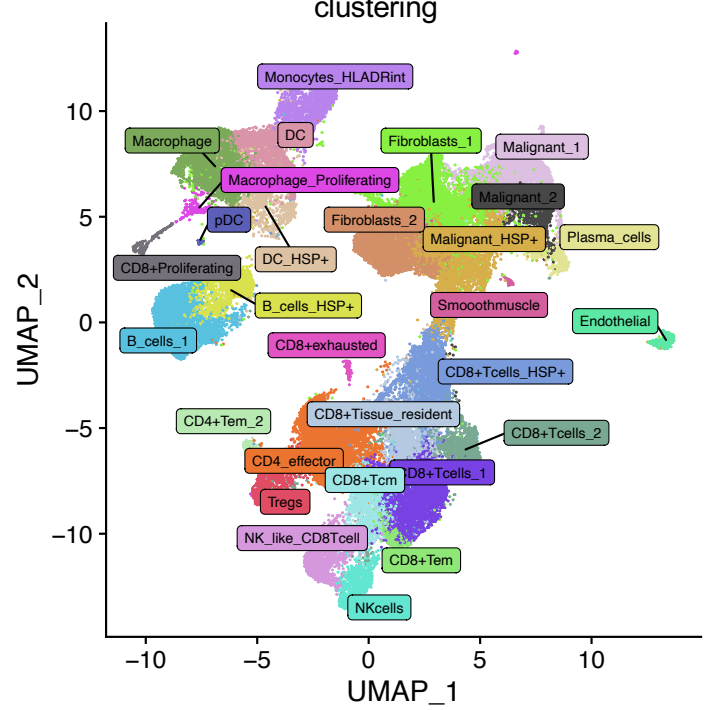

B.

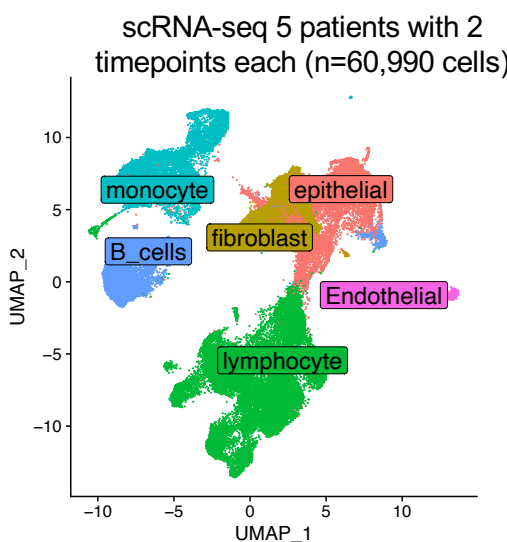

E.
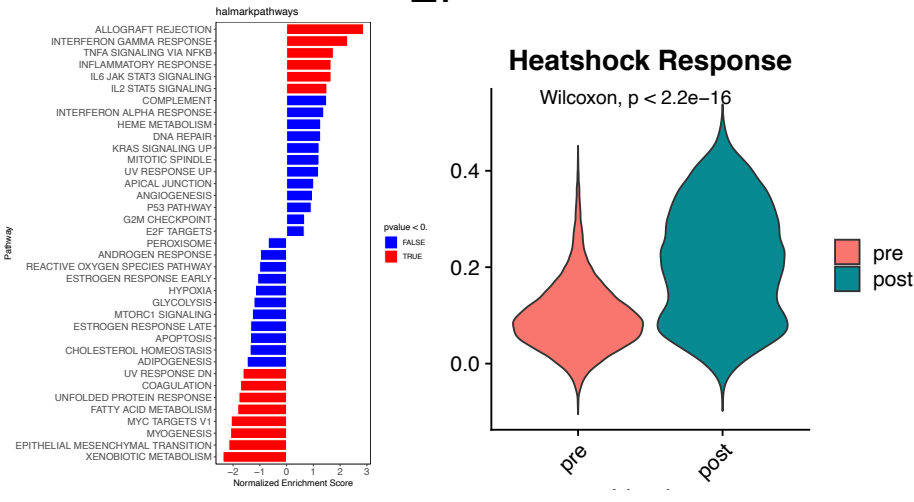

G.

Paired comparison identifies changes in heat shock positive immune cells post treatment

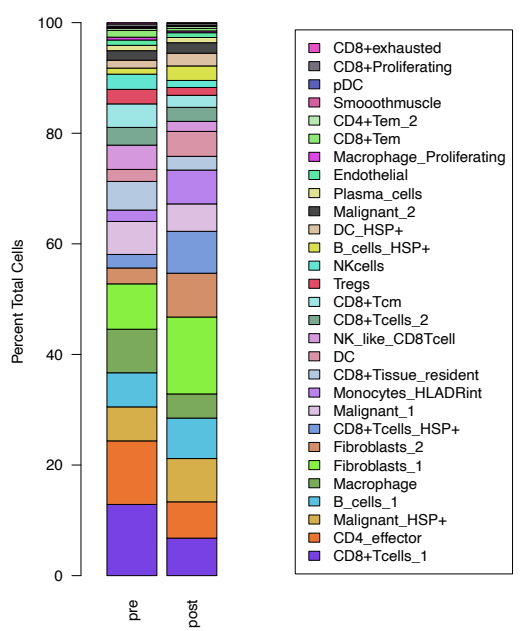

Fig. 2. Single Cell RNAseq analysis of pre- and post-HIPEC treated specimen identifies heat shock responsive immune cells. A. Schematic representation of the flow of tissues collection and processing for single cell RNA sequencing. A tumor specimen is taken immediately before and after HIPEC administration (90 minutes) at the time of interval debulking surgery. Specimens are obtained from the same site (omentum) to reduce variability. Tumor samples are dissociated into a single cell 
suspension and followed by scRNA-seq to identify cell types and gene expression profile. B. UMAP representing $n=10$ samples from $n=5$ patients with 2 timepoints each, showing the general cell type classifications B. C. Differential gene expression comparing Post-Treatment and Pre-Treatment samples $n=5$ for each group. D. Hallmark pathway analysis using GSEA (gene set enrichment analysis) and the HALLMARK gene sets based of the differential expression analysis of post vs pretreatment samples overall. E. Pathway analysis of the Gene Ontology biological process Response to Heat pathway gene set $n=161$ genes analyzed and scored for each cell from all $n=5$ samples pretreatment and $n=5$ samples post-treatment. $F$ UMAP representing the unsupervised clustering analysis of all $n=10$ samples with detailed naming based on gene expression. $G$ comparison of the overall percentages of each cell type present for all pre $n=5$ and all post $n=5$ treatment samples.

\section{HIPEC induces a rapid heat shock response in CD8 T cells.}

After identification of the heat shock pathway increases, we sought to understand which cell type or types were most responsive to heat. In scoring each of the 29 unique cell types for heat shock response GO pathway pre and post treatment we identified significant increases in all populations (Fig. 3A, Supplemental Fig 6), with the highest signal coming from CD8+ T cells we termed HSP+ (heat shock protein positive). We performed a cell cycle scoring within Seurat V4 and determined the CD8 T cells were in $\mathrm{G} 2 / \mathrm{M}$ phases suggesting they are highly proliferative within the tumor microenvironment (Supplemental Fig. 7A). Visualization via UMAP representation shows that while this population exists both pre and post treatment, it is robustly increased post treatment (Supplemental Fig. 3B). Differential expression of the CD8+ T cells HSP+ pre and post treatment demonstrated that the majority of the signal is derived post treatment (Fig. 3C). Density plot analysis of the UMAP further represents the focal intensity of the Heat Shock pathway in these T cells as well as a weak and more general response in the epithelial and fibroblast populations (Fig. 3D). Pathway analysis of the differential expression analysis post vs pre-treatment demonstrated a robust increase in immune activation pathways (Fig. 3E) including TNF alpha (Fig. 3F) and Interferon Gamma (Fig. 3G) signaling, which was further verified as being related to the $\mathrm{HSP}+\mathrm{CD} 8$ population. Furthermore, we sought to determine the source of CD8 T cell immune activation by heat and reasoned that one possibility might be that the DNA damage caused by heat, that we observed in vitro, could act to signal CD8 activation through the cGAS/STING pathways. Analysis of CGAS expression demonstrated that the HSP+ CD8 T cells upregulated CGAS expression compared to other cells and upregulated it post treatment (Fig. $\mathbf{3} \mathbf{H}, \mathbf{I})$. 
Furthermore, joint density mapping of CGAS expression and Heat shock response pathway demonstrated a co-expression of the two pathways specifically in the HSP+ CD8 T cell population (Fig.

A.

Heat Shock Response

Fig. 3

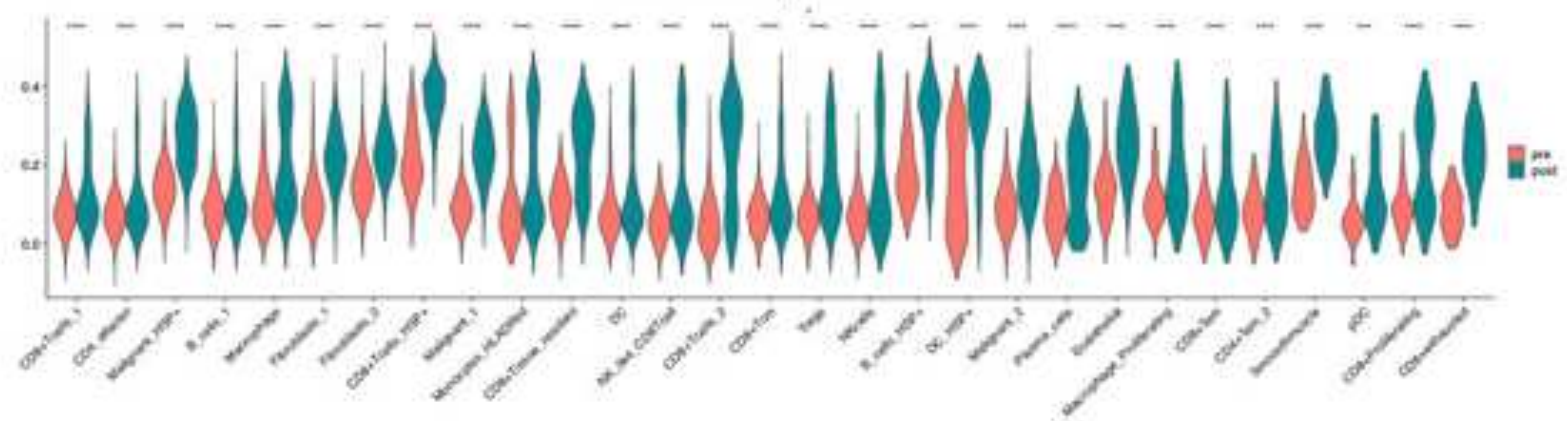

B. Heat Shock Response

C. Pathway

CD8+ T cells HSP+

D.

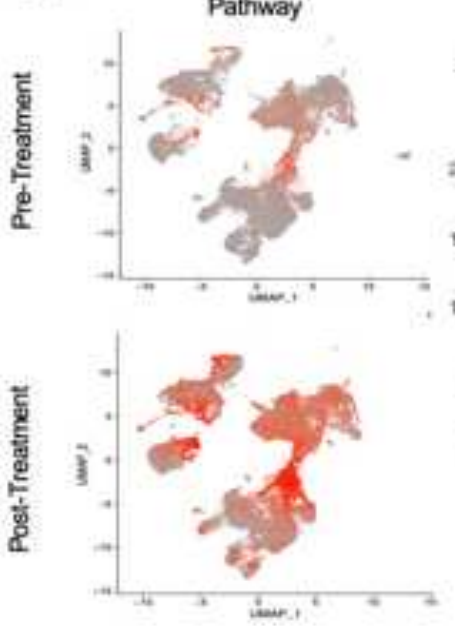
selected comparison
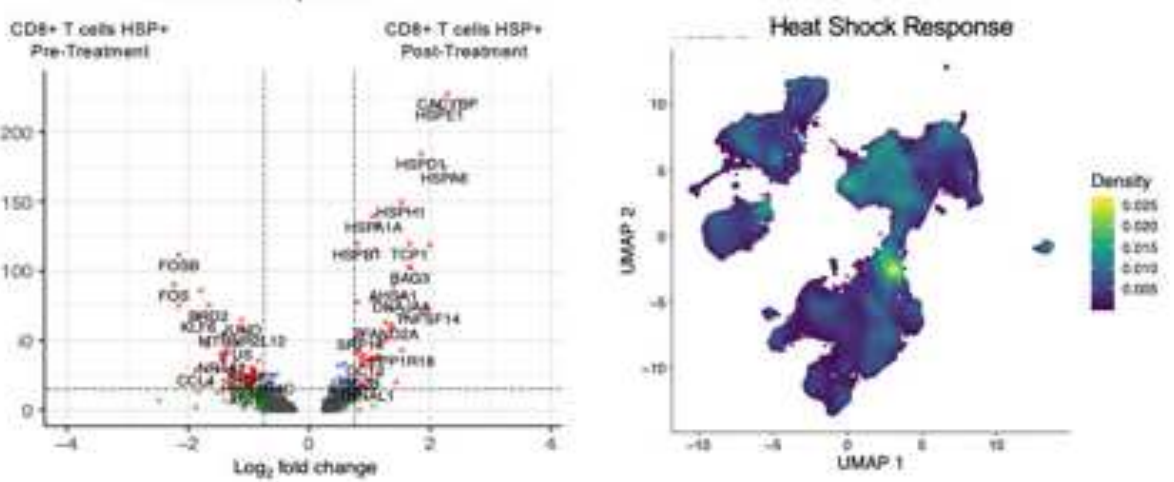

E.

F.

G.

$\mathrm{H}$.
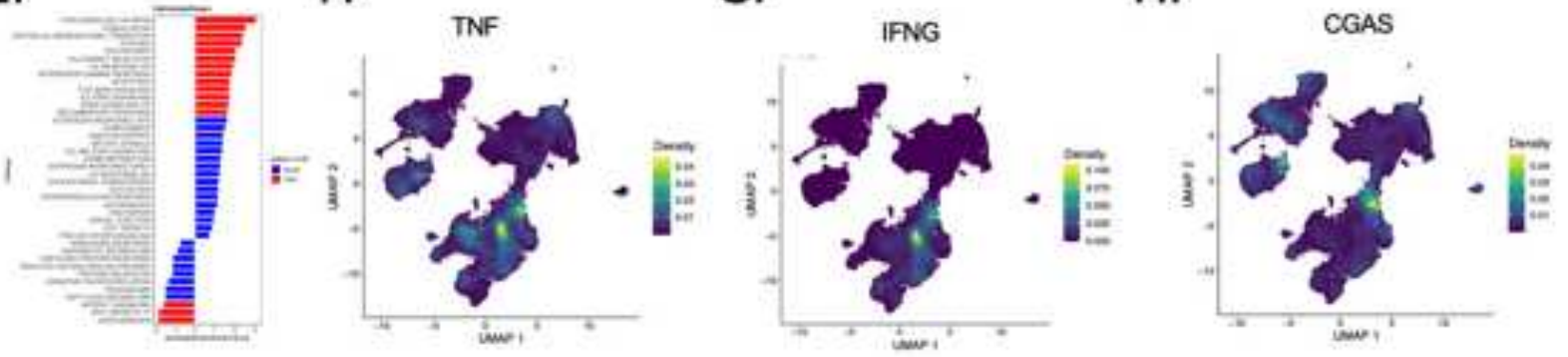

I.

J.
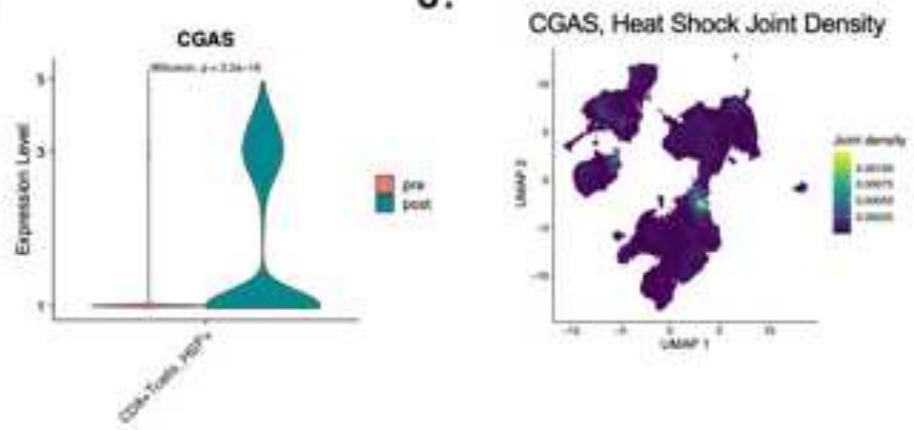
Fig. 3. A. Heat shock pathway was scored for each individual cell for the $n=5$ samples pre-treatment and $n=5$ samples post treatment and graphed via violin plots for distribution across all cell types identified. B. UMAP representation of the sample cells pre and post treatment, colored by their expression level of the GO biological process response to heat pathway. C. Differential expression analysis of the $n=5$ pre and $n=5$ post treatment CD8+ T cell HSP+ subset. D. Density plot representing the distribution of cells expressing the $G O$ biological process response to heat pathway. Hallmark pathway analysis from the differential gene expression of HSP+ CD8 T cells post vs pretreatment graphed as NES score on the $x$-axis and colored by the $p$-value with red showing $p<0.05$. F-H. Density plots of TNF alpha expression, interferon gamma expression, and CGAS expression across all $n=10$ samples pre and post-treatment. Violin plot demonstrating the distribution of CGAS expression in the CD8 T cells HSP+ population pre vs. post-treatment. J. Joint Density plots of CGAS and Heat shock response pathway across all $n=10$ samples pre and post-treatment.

\section{Dendritic cells respond to hyperthermia in a similar mechanism to CD8+ T cells via CGAS upregulation}

In seeking to further understand how CGAS upregulation is involved the response to hyperthermia, we took a closer look at CGAS expression across the 29 cell types and identified B cells and Dendritic cells with similar increases in CGAS expression (Supplemental Fig. 7B). These populations were also identified by an increased in heat shock protein expression compared to their similar cell types (Supplemental Fig. 4B). These clusters can also be noted for their increase in heat shock response pathways like CD8+ $T$ cells as seen in the UMAP representation in Fig. 3B, D). Sub-setting this dendritic cell population (Fig. 4A), we performed differential gene expression and pathway analysis comparing post and pre-treatment (Fig. 4B, C). Pathway analysis showed similar results to the CD8+ T cells response and the overall response to hyperthermia treatment with increased immune activation and a significant increase in CGAS expression (Fig. 4C). Focusing on the activation of dendritic cells we further investigated the MHC class I and II expression as a measure of their activation status, which revealed a significant increase in HLA-A, B, C and HLA-DRA post treatment (Fig 4D). 
Fig. 4

A

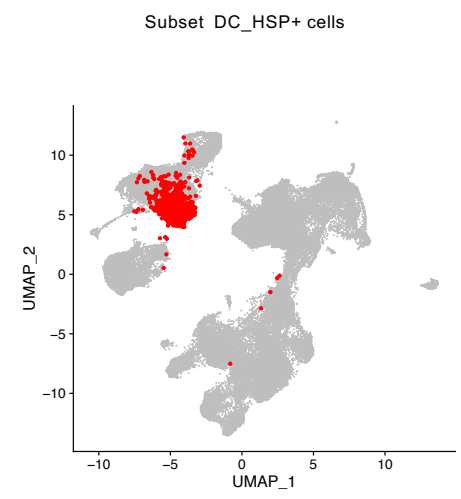

D.

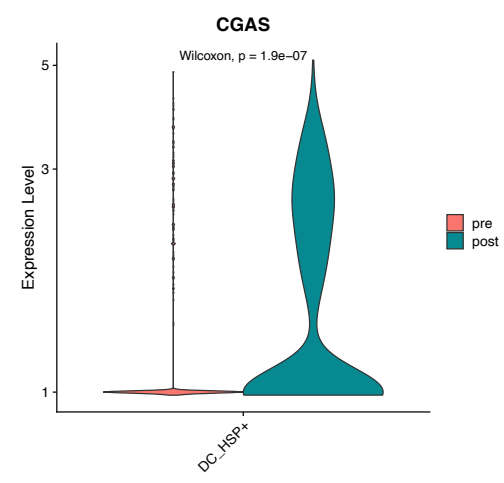

B.

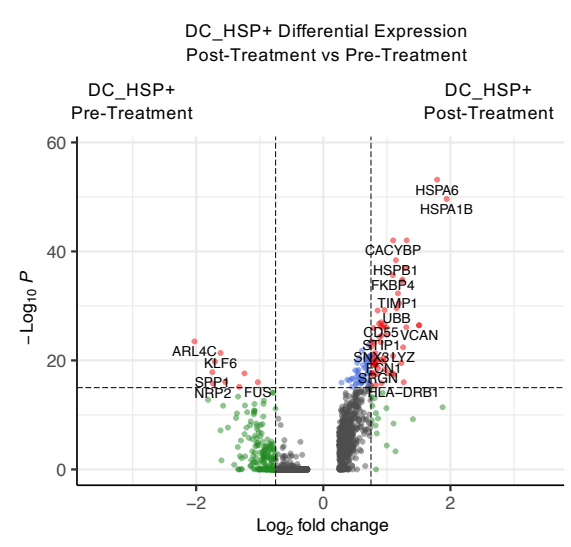

E.
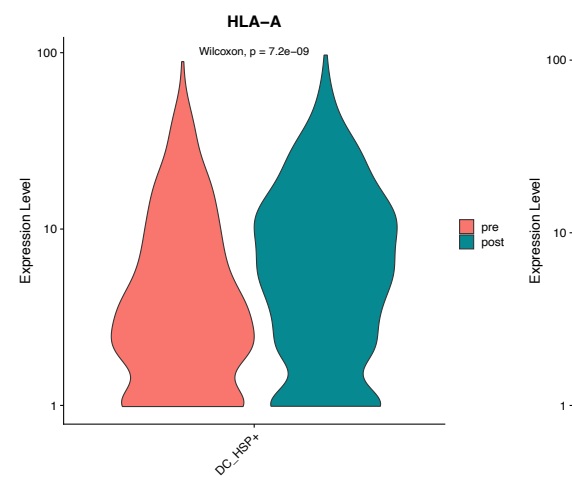

C.
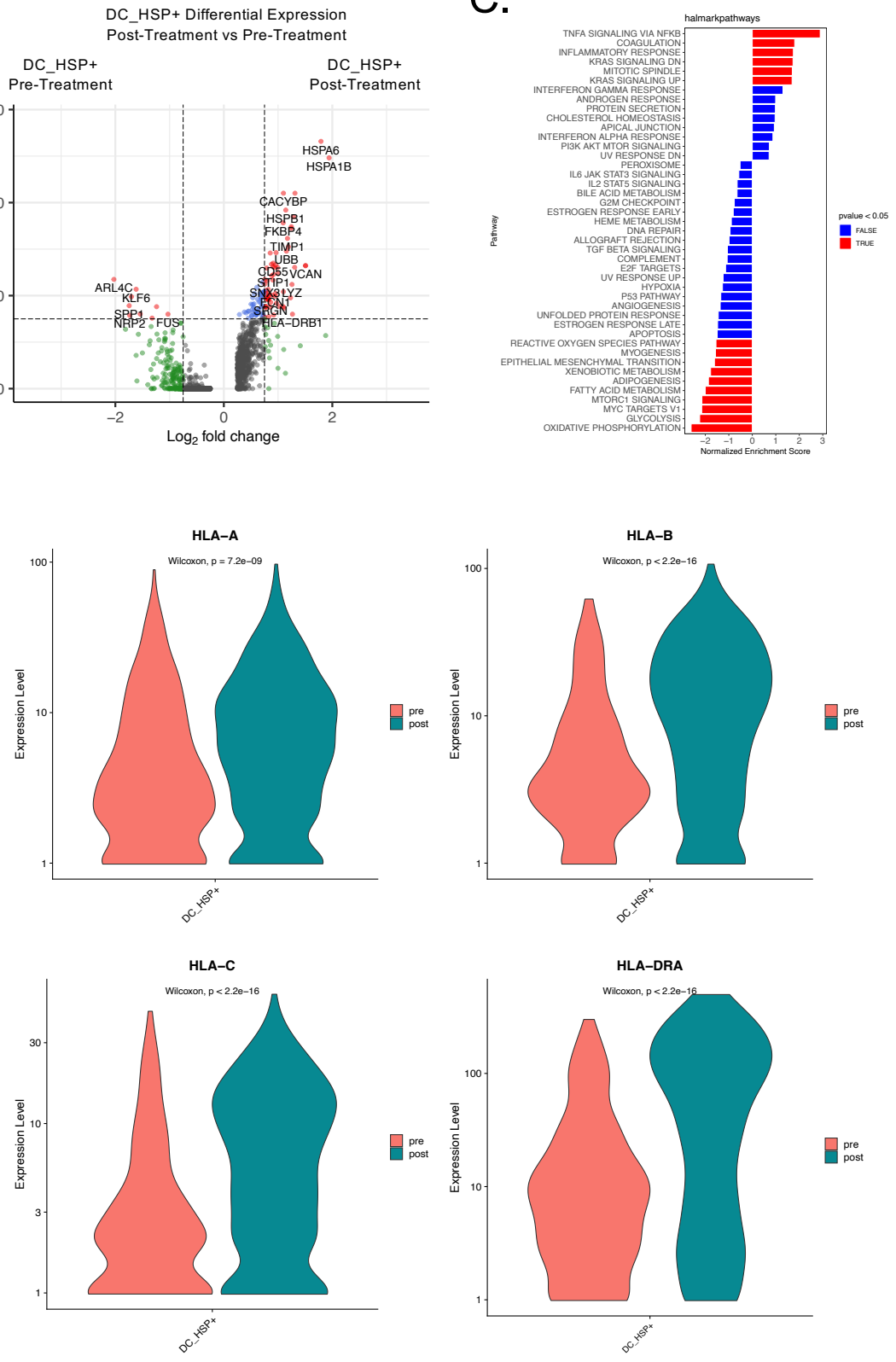

$\mathbb{Z}_{\text {pos }}^{\text {pos }}$

$\nabla_{\text {Doout }}^{\text {pou }}$

Fig. 4. cGAS inflammatory pathway is induced in dendritic cells of HIPEC specimen. A. Representative UMAP showing the cells that were selected for sub-setting the Dendritic Cell population defined by its heat shock positive protein signature. Differential expression analysis of the $n=5$ pre and $n=5$ post treatment Dendritic Cells HSP+ cell subset. Hallmark pathway analysis from the differential gene expression of HSP+ Dendritic cells post vs pre-treatment graphed as NES score on the $x$-axis and colored by the $p$-value with red showing $p<0.05$. D. Violin plot of CGAS expression and HLA expression between the pre and post treatment cells from the DC HSP+ cell population. Wilcoxon with multiple comparisons Bonferroni correction were performed for $\mathrm{D}, \mathrm{E}$ comparisons. 


\section{Hyperthermic cisplatin administration in an EOC mouse model leads to tumor growth}

inhibition dependent on immune cells.

In seeking to determine the importance of the immune system in HIPEC treatment response, we generated a rapid, medium-throughput mouse model of HIPEC. In this model, an IP injection of cisplatin into tumor-bearing mice is made while applying $40 \mathrm{C}$ heat to the abdomen. Heat is maintained for up to 30 minutes. Subsequently, tumor growth is monitored over a 2 week period with weekly injections of cisplatin (Fig. 5A). C57BI/6J immune competent mice injected with ID8-luc cells were treated with vehicle at normothermic (V37), hyperthermic (V42), and cisplatin at normothermic (C37) or hyperthermic (C40) conditions. Vehicle treated mice exhibited no difference in overall tumor growth (Fig. 5B). In contrast, mice treated with cisplatin exhibited a dose dependent suppression of tumor growth with significantly greater suppression of tumor growth in 40C treated mice (Fig 5B). Our scRNAseq findings point to rapid induction heat shock and inflammatory response in immune cells including CD8+ T cells, B cells, and dendritic cells (DCs). At endpoint, we harvested tumors and processed samples for flow cytometry of immune and myeloid cells. We observed tumor infiltration of CD3+ $T$ cells with a higher proportion of CD8+ $T$ cells within 24 hours in $40 \mathrm{C}$ treatment that was significantly higher than 37C treated mice (Fig. 5C). The increase in CD8+ T cells was heat dependent as we did not detect a difference between vehicle (V40) and cisplatin (C40) treated tumors (Fig. 5C). By 2 weeks, tumors from mice treated with hyperthermic cisplatin exhibited greatest infiltration of CD3+, CD4+, CD8+, and regulatory $T$ cells compared to $\mathrm{V} 40, \mathrm{C} 37$, and $\mathrm{V} 37$ treated mice (Fig. 5D). This suggests short term (20 min) hyperthermic cisplatin exposure can lead to long term immune response that is maintained with continued cisplatin exposure. In contrast, we did not observe difference in myeloid populations after 24 hour or 2 weeks (Supplemental Fig. 8A, B). These results led us to hypothesize that the immune system is necessary for hyperthermic cisplatin benefit. To test the impact of the immune system, we repeated the study in immune deficient NSG mice. Mice were injected with ID8-luc cells and monitored for tumor growth followed by hyperthermic or normothermic treatment in presence or absence of IP cisplatin. In contrast to immune competent mice, NSG mice exhibited no benefit of hyperthermic treatment on efficacy of cisplatin (Fig. 5E). These findings support the 
hypothesis that the efficacy of hyperthermic chemotherapy treatment of peritoneal tumors depends in part on an intact immune system.

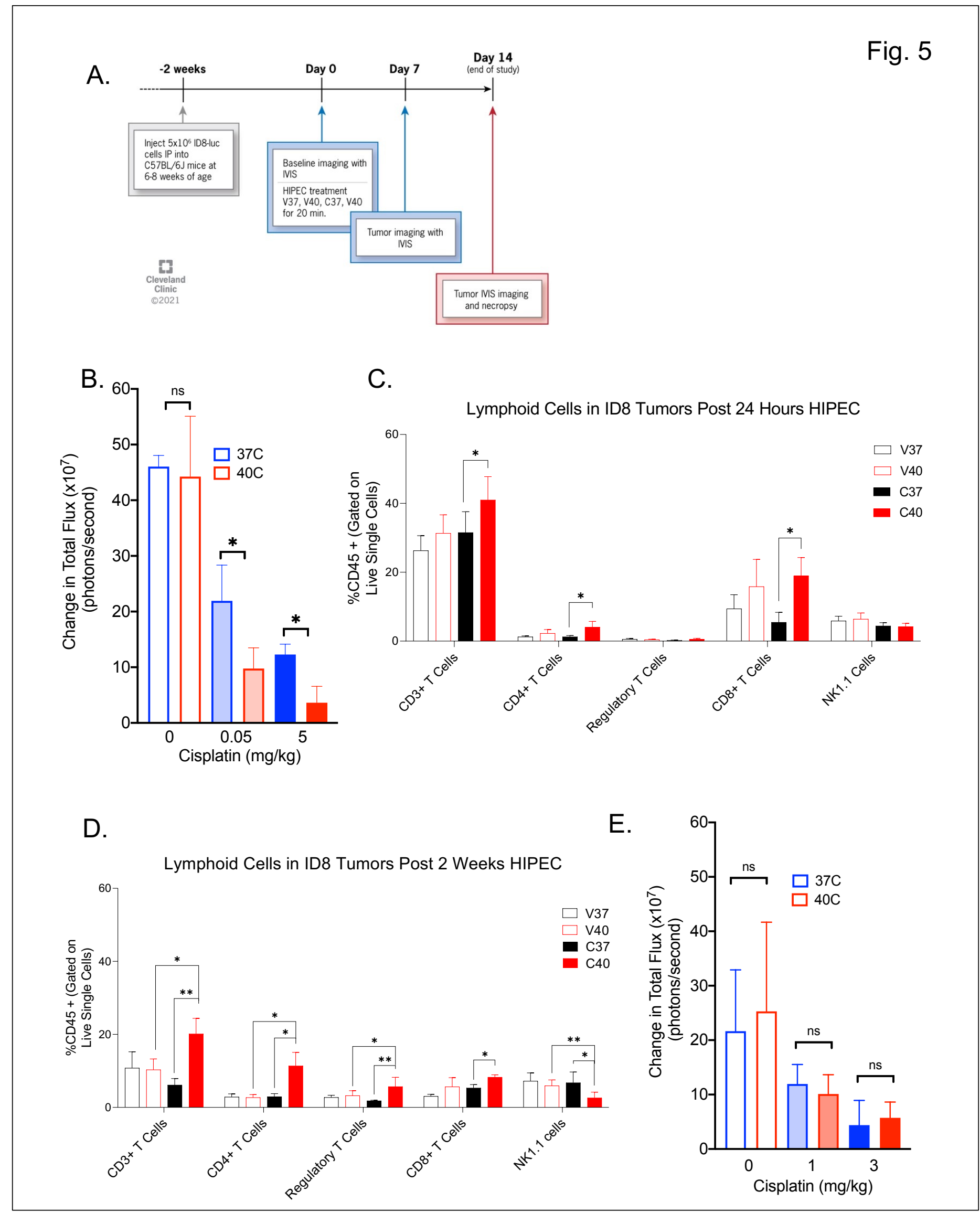


Figure 5. Treatment of mouse epithelial ovarian cancer with heated cisplatin leads to increased efficacy in immune competent but not in immune deficient mice. A. Detailed schematic of animal HIPEC protocol. ID8-luc, a EOC mouse line, is inoculated into immune competent C57BL/6 or immune deficient NSG mice intraperitoneally. Tumor establishment and growth is confirmed using In Vivo Imaging System (IVIS) optical spectrum. Varying concentrations of cisplatin is injected and superficial hyperthermia at $40 \mathrm{C}$ or normothermia (37C) is applied using an FDA approved hyperthermia unit (BSD500) for 20 minutes. IVIS assessment is performed weekly thereafter to monitor tumor size and growth following the treatment. B. Effect of hyperthermic cisplatin treatment of murine EOC model in immune competent $\mathrm{C} 57 \mathrm{BI} / 6 \mathrm{~J}$ mice. Tumor bearing $\mathrm{C} 57 \mathrm{BI} / 6 \mathrm{~J}$ mice are treated for 20 minutes with no heat $(37 \mathrm{C})$ plus varying concentrations of cisplatin $(0,0.05,5 \mathrm{mg} / \mathrm{kg})$ or heat $(40 \mathrm{C})$ plus varying concentrations of cisplatin $(0,0.05,5 \mathrm{mg} / \mathrm{kg})$. Change in tumor growth relative to normothermic controls is shown. Representative data from experiments replicated 3 times. $\left(n=6 /\right.$ condition, $\left.{ }^{*} p<0.05\right)$. C. Lymphoid and myeloid population analysis two weeks post normothermic and hyperthermic cisplatin treatment. Lymphoid populations are enriched in ID8 tumors following HIPEC treatment. C. 24 hours following HIPEC therapy, CD3, CD4, and CD8 T Cells were enriched in tumors treated with heat and cisplatin (C40) compared to cisplatin treatment alone (C37). D. 2 weeks following HIPEC therapy CD3, CD4, Regulatory, CD8, T cells were enriched in tumors treated with heat and cisplatin (C40) compared to cisplatin treatment alone (C37) and compared to heat alone (V40). $n=5$ mice per group ${ }^{*} p<0.05$, ${ }^{* *} \mathrm{p}<0.01$, FDR T Test E. Effect of normothermic and hyperthermic cisplatin treatment of murine EOC model in immune deficient mice. Tumor bearing NSG mice are treated for 20 minutes with no heat $(37 \mathrm{C})$ plus varying concentrations of cisplatin $(0,1,3 \mathrm{mg} / \mathrm{kg})$ or heat $(40 \mathrm{C})$ plus varying concentrations of cisplatin $(0,1,3 \mathrm{mg} / \mathrm{kg})$. Change in tumor growth relative to normothermic controls is shown. Therapeutic response remains unchanged in hyperthermic versus normothermic cisplatin treated mice. Dose dependent suppression of tumor growth in response to cisplatin therapy is observed (cisplatin dose $0,1,3 \mathrm{mg} / \mathrm{kg}$ ) with no impact of heat on efficacy in absence of immune system. Representative findings from a study that was repeated 2 times. $(n=5, p<0.05)$. 


\section{Discussion.}

Cell culture studies reveal rapid induction of DNA damage pathways but limited insights on

patient outcomes. Our findings highlight the limitation in elucidating the mechanisms of hyperthermia and cisplatin in an isolated system such as a cell culture system. We show a rapid induction of heat shock response within 90 minutes as well as cisplatin increase in DNA damage. The increase in cisplatin adduct formation within 90 minutes of heat treatment is consistent with studies indicating hyperthermia enhances chemotherapy absorption ${ }^{11,12}$. Despite the increase in DNA damage, we found limited impact on cell viability and modest improvement in sensitization to cisplatin in EOC cells. These findings are consistent with studies on impact of hyperthermia on cancer cell behaviors ${ }^{13}$. Single-cell RNAseq analysis provided key insights on the rapid, within 90 minutes, induction of heat shock response. Indeed, induction of heat shock pathways is observed in other systems with similar kinetics. The ability to detect heat shock response within 90 minutes provided rationale and feasibility to examine the impact of hyperthermia in clinical tumor specimen.

scRNAseq identifies landscape of ovarian cancers in the omentum. Human EOC tumors are heterogeneous, containing diverse cellular populations (e.g. differentiated tumor cells, fibroblasts, inflammatory cells, endothelial cells, cancer stem cells (CSCs)) in a highly dynamic microenvironment that regulates tumor growth ${ }^{14}$. Our single cell RNAseq analysis focused on omental tumor tissue before and after HIPEC to reduce sample to sample variability. We opted not to perform bulk RNA-seq as gene expression changes are lost as RNA is extracted en masse from the tumor and changes in gene expression over-represent the most abundant cell types ${ }^{15}$. In contrast, scRNA-seq allows for measurement of gene expression changes within all identified cell types within a heterogeneous tumor $^{16}$. With this strategy, we identified the major populations including epithelial ovarian cancer cells, cancer-associated fibroblasts, stromal cells, and multiple immune cell populations ${ }^{17}$. In this regard scRNA-seq is ideally suited to analyze HIPEC-induced gene expression within a complex tumor microenvironment To our knowledge, this approach has never been applied to the study solid tumors in humans ${ }^{18}$. 
The studies are unprecedented allowing us to identify the cells at various stages of the cell cycle and we determined that regardless of treatment the lymphocytes are highly proliferative within the tumor. By analyzing primary patient tumors pre- and immediately post-HIPEC, we identified the immune cell populations are most sensitive to heated cisplatin treatment in the tumors.

HIPEC treatment activates primarily B-, T-, and antigen presenting dendritic cells. HIPEC mechanism of action is poorly defined and here we identify rapid activation of the immune system. We define the tumor microenvironment in the omentum and identify the major cells that comprise the tumor allowing us to define the cellular and molecular heterogeneity. Analysis of heat shock response pathways within the cellular populations indicates that a subset of cells is responsive to hyperthermia ${ }^{19}$. It is striking that the malignant epithelial cells are not the cells most heat responsive. The heat responsive populations were a subset of CD8+ T cells, B cells, and dendritic cells. The evidence for a role of the adaptive immune response is complemented by our mouse findings indicating an intact immune system is necessary for efficacy in a mouse model of HIPEC. This is a particularly important finding as there is a growing understanding that hyperthermia enhances immune response via multiple mechanisms including disruption of immune suppression ${ }^{20}$. Our studies advance these findings and potentially lead to HIPEC treatment in combination with immunotherapy.

Mouse model provides pre-clinical proof of concept for essential role of immune system. Studies on HIPEC animal models provide a paradigm for exploring the impact of hyperthermia and cisplatin on the tumor microenvironment with potential for application of related agents ${ }^{9,10}$. This provides much needed strategy to bridge the gap between in vitro work exploring HIPEC mechanism and the limitations of working with patient tumor within the context of standardized HIPEC therapy. The development of this noninvasive paradigm in mice provides us an opportunity to test treatment strategies for patients with advanced EOC and provide a basis for targeted drug design and development of cancer therapeutics.

We determined that hyperthermic cisplatin treatment of immune-competent mice injected with murine epithelial ovarian cancer exhibit significant attenuation of tumor growth compared to normothermic 
cisplatin treatment. This model provides an opportunity to address questions that can be applied to the clinic. For example, what is the relative contribution of heat and cisplatin? Our findings indicate that heat alone is not sufficient for the survival benefit, rather it is the combination with cisplatin. Our data provide pre-clinical insight to this question and demonstrates that, in fact, hyperthermia augments the tumorstatic effects of cisplatin and hyperthermia alone has no impact on tumor growth.

HIPEC link to cGAS-STING and antitumor activity. Our single cell RNAseq findings that the cytosolic DNA sensor, cGAS, is induced in heat shock induced CD8+ T, B, and dendritic immune cells provides new insights on the interplay between DNA damage pathways and activation of antitumor immunity. cGAS is a cytosolic DNA sensor that activates Stimulator of Interferon Genes (STING) with downstream activation of interferon and inflammatory pathways ${ }^{21}$. Thus, cGAS-STING signaling has emerged as a pathway for pharmaceutical intervention ${ }^{22,23}$. These findings complement the literature and identify a new mechanism to activate antitumor activity via hyperthermia treatment in combination with activation of DNA damage. Importantly, there are multiple therapeutic modalities that could provide enhanced response including DNA damage agents (e.g. PARP, ATM, Checkpoint kinase, Topoisomerase, DNA crosslinking) as well as anti-metabolite and microtubule targeting pharmaceuticals ${ }^{21}$. Checkpoint kinase, Topoisomerase, DNA crosslinking) as well as anti-metabolite and microtubule targeting pharmaceuticals ${ }^{21}$. Cisplatin and paclitaxel (a microtubule - stabilizing agent) have shown efficacy in combination with hyperthermia in patients in retrospective analyses (DeBernardo, R., personal communication).

Identification of novel therapeutic strategies and understanding their mechanism of action is a priority for EOC. Here, we undertook a comprehensive strategy to interrogate the underlying mechanism of HIPEC with a focus on clinical specimens obtained pre- and post-treatment and identified a primary mechanism of HIPEC to be activation of CD8 T cells. These new insights may indicate utility in combination immunotherapeutic approaches in EOC, using hypothermic treatment alongside longerterm immune activating approaches such as immune checkpoint inhibitors. During these investigations we also developed and utilized a novel noninvasive murine model to investigate the impact of 
hyperthermic cisplatin in vivo. The development of this noninvasive paradigm in mice provided us the opportunity to study the immunologic impacts of HIPEC and will allow for future development of therapeutics. 


\section{Acknowledgements.}

We gratefully appreciate the insights from the Reizes and Lathia laboratories. The studies were facilitated by shared lab resources at the Lerner Research Institute including the digital imaging microscopy, flow cytometry, genomics, and small animal imaging. These studies were supported by the VeloSano Bike to Cure, Cleveland Clinic Center of Excellence in Gynecologic Cancer, and The Laura J. Fogarty Endowed Chair in Uterine Cancer Research. We would like to thank Dr. John J, Turchi and Pamela S. VanderVere-Carozza, in the Departments of Medicine and Biochemistry\& Molecular Biology, Indiana University School of Medicine for the cisplatin adduct analysis in A2780 ${ }^{\mathrm{CP}}$ cells. This work utilized the Leica SP8 confocal microscope that was purchased with funding from National Institutes of Health SIG grant 1S100D019972-01 and the PerkinElmer IVIS Spectrum CT In Vivo Imager that was purchased with funding from National Institutes of Health SIG grant 1S100D018205$01 \mathrm{~A} 1$.

\section{Author contributions}

TJA supported the scRNAseq analysis and wrote sections of the manuscript

$\mathrm{MH}$ performed all the in vitro studies and critically reviewed the manuscript

DC performed the mouse studies and critically reviewed the manuscript

ZA developed the mouse hyperthermia model and critically reviewed the manuscript

EE performed the bioinformatics analysis, developed the immune profiling panels, and wrote parts of the manuscript

GD assisted in the cisplatin in vitro analysis and critically reviewed the manuscript

$\mathrm{CH}$ analyzed the sequencing data from in vitro and scRNAseq studies

THH analyzed the sequencing data from in vitro and scRNAseq studies

VK developed scRNAseq algorithms for human studies

JDL provided insights throughout the development of the studies from initial in vitro studies through mouse studies and critically reviewed the manuscript

$P Q$ assisted in development of mouse hyperthermia model

JSY provided insights on development of mouse hyperthermia model and critically reviewed the manuscript

CMM provided surgical specimen, critically reviewed the specimen collection strategy, and reviewed the manuscript

TAC assisted in immune analysis of scRNAseq data and critically reviewed the manuscript 
RLD conceived the surgical strategy for specimen collection of scRNAseq, wrote parts of manuscript, and critically reviewed manuscript

OR conceived, organized, and wrote the manuscript

Competing interests

Authors report no conflicts of interests. 


\section{Methods}

\section{Materials and Reagents.}

A2780, A2780 $\mathrm{CP}$, OV81, OV81 ${ }^{\mathrm{CP}}$ (human), ID8, and ID8-VEGF (syngeneic) EOC cell lines were cultured in Dulbecco Modified Eagle Medium (DMEM) media containing heat inactivated $10 \%$ FBS (Atlas Biologicals Cat \# F-0500-D, Lot F31E18D1) and grown under standard conditions. All cell lines were checked routinely to ensure mycoplasma free conditions.

\section{In vitro Cisplatin Sensitivity Studies.}

Cells were plated at 1,000 cells per well (96-well plate) and treated with either cisplatin $(0.1,0.3,1,3$, 10, $30 \mu \mathrm{M}$; Spectrum Chemical) or vehicle (normal saline) at either $37^{\circ} \mathrm{C}$ or $42^{\circ} \mathrm{C}$ for 90 minutes. Cells were then transferred to $37 \mathrm{C}$ for an additional 72 hours. Cell viability was measured using Cell Titer Glo (Promega). $n=6 /$ condition, data analyzed using PRISM 9.0.

\section{Cisplatin adduct analysis}

A2780CP cells were treated with hyperthermia and cisplatin. After treatment, cells were frozen in freezing media until DNA extraction. DNA was extracted from cells by lysis and spooling as previously described ${ }^{24}$, a modified protocol based on Laird et al, $1991^{25}$. Briefly, cells were pelleted and washed once with PBS. Cells were resuspended in lysis buffer and incubated overnight at 37 degrees C. After lysis, an equal volume of isopropanol was added, and DNA was spooled onto a closed Pasteur pipet. DNA was washed with $70 \% \mathrm{EtOH}$ and resuspended in water. DNA $(30 \mu \mathrm{g})$ was hydrolyzed overnight in $1 \%$ nitric acid at $70^{\circ} \mathrm{C}$ in a $200-\mu l$ total volume. Samples were analyzed by inductively coupled plasma-mass spectrometry (ICP-MS) at Keystone Bioanalytical North Wells, PA).

\section{Western Blot Analysis}

Immunoblot experiments were performed based on our established methods ${ }^{26}$. Briefly, cells were grown in $100 \mathrm{~mm}$ dishes and treated with vehicle or cisplatin, placed in $37^{\circ} \mathrm{C}$ or $42^{\circ} \mathrm{C}$ incubator for 90 minutes then incubated for 72 hours at $37^{\circ} \mathrm{C}$. Following treatment, cells were washed with cold D-PBS and lysed in NP-40 lysis buffer (Invitrogen, USA) containing $250 \mathrm{mM} \mathrm{NaCl}, 50 \mathrm{mM}$ Tris, pH 7.4, $50 \mathrm{mM}$ NaF, 1 mM Na3VO4, 5 mM EDTA, 1\% Nonidet ${ }^{\mathrm{TM}}$ P40 (NP40), and 0.02\% NaN3. PMSF and protease inhibitor cocktails (Sigma, USA) were added freshly. During lysis, samples were vortexed occasionally and maintained on ice for one hour. Samples were harvested and centrifuged at 10,000 rpm for $10 \mathrm{~min}$ 
at $4^{\circ} \mathrm{C}$. After centrifugation, clarified protein lysates were collected and protein concentrations determined using BCA kit (Thermo Scientific, USA). $\beta$-mercapto ethanol containing $6 \times$ Laemmli dye was added to the lysates, samples were then boiled for $6 \mathrm{~min}$, and resolved on SDS-PAGE (Bio-Rad, USA). After gel electrophoresis, proteins were immobilized onto PVDF membranes (Millipore, USA) by wet transfer method overnight at $4^{\circ} \mathrm{C}$. Membranes were blocked in blocking buffer containing $5 \%$ bovine serum albumin in TBST (Tris-buffered saline containing $0.1 \%$ tween 20 ) for $1 \mathrm{hr}$ at room temperature. Membranes were incubated in primary antibodies, $\gamma \mathrm{H} 2 \mathrm{AX}$. (1:1000, Cell signaling, USA) and GAPDH (1:6000, Proteintech, USA) overnight at $4^{\circ} \mathrm{C}$, followed by three washes with TBST, and incubated with secondary antibodies for one hour at RT. After a final 3 washes in TBST, membranes were incubated in chemiluminescence solution (PerkinElmer, USA) and images were captured by GE Amersham Imager 600 system (GE Healthcare, USA).

\section{Immunofluorescence Staining.}

To visualize $\gamma \mathrm{H} 2 \mathrm{AX}$ foci, cells were processed based established methods with few modifications ${ }^{27}$. Briefly, cells were grown on glass coverslips in 6-well plates and following treatment, were washed once with D-PBS. Cells were fixed in 4\% paraformaldehyde (Electron Microscopy Sciences, USA) in D-PBS for 10 minutes at room temperature. Following fixation, cells were washed two times with DPBS and incubated in $0.01 \%$ triton X-100 solution for $5 \mathrm{~min}$. Cells were then washed and blocked with buffer containing $2 \%$ Goat serum (Thermo Scientific, USA) and 3\% BSA (GoldBio, USA) in TBST (Trisbuffered saline containing $0.1 \%$ tween 20 ) followed by incubation with anti- $\gamma \mathrm{H} 2 \mathrm{AX}$ antibody (PhosphoHistone H2A.X, Ser139, Cell signaling, USA) overnight at 4C. Cells were washed with TBST four times

and incubated with Alexa Fluor 568 conjugated secondary antibody (Invitrogen, USA) for one hour at room temperature and washed with TBST for three times. Coverslips were mounted on glass slides using Vectashield mounting media containing DAPI (Vector Lab, USA). Images were captured by confocal Leica Microscope in oil emersion. Image J software was utilized for foci counting.

\section{RNA Isolation and Sequencing.}


Following RNA isolation, cDNA libraries were prepared by the LRI Genomics Core facility and sent to Macrogen Inc. for RNA sequencing. Differential Gene Expression Analysis from RNA-Seq Data was performed as follows:

An average of $60.6 \mathrm{M}$ paired-end reads in $150 \mathrm{bp}$ sequenced from 24 samples. After either Illumina universal adapters or lower quality bases at the 3-prime end are trimmed (cutadapt $1.16^{28}$, the average read length is shortened to $137 \mathrm{bp}$. The quality-controlled RNA-seq reads are converted to transcriptome abundant matrix in the format of TPM (Transcripts Per Kilobase Million ${ }^{29}$ ) via Salmon v0.14.130 with 'libType=A' and all others remain in a default setting. The Salmon reference genome sequence index is built on a reference (GRCm38.p01) with a gene model (human GENCODE v.29) covering a total of 205,870 transcripts. The differential gene expression analysis is conducted with DESeq2 v1.22.2 $2^{31}$ where size factor and dispersion estimation were performed with default settings. In total, 8 DEG analyses are performed between two sample groups (i.e., C37-72h vs. C4272h, V37-72h vs. C37-72h, V37-90 vs. C37-90, V42-72h vs. C42-72h, C37-90 vs C42-90, V37-72h vs. V42-72h, V37-90 vs. V42-90, and V42-90 vs. C42-90) and all DEG with FDR (false discovery rate via Benjamini and Hochberg multiple testing adjustment $)<0.05$.

\section{GSEA Analysis.}

We initially applied GSEA (utilizing GSEA software, a joint project of UC San Diego and Broad Institute) to the following gene set comparisons: V42 over V37, C42 over C37, and C42 over V42 treated CP70 cells (Chip platform:Human_ENSEMBL_Gene_ID_MSigDB.v7.4.chip ), to summarize well-defined biological conditions of the original founder sets. The h.all.v7.4.symbols.gmt (Hallmark),

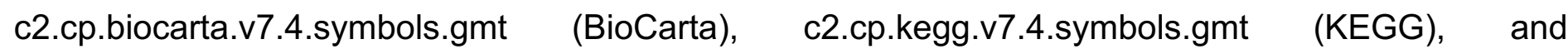
c2.cp.reactome.v7.4.symbols.gmt (Reactome) datasets were obtained from the GSEA website MsigDB database. Enrichment analysis was performed by default weighted enrichment statistics, with the random combinatorial count set as 1,000 and the exclusion of gene sets with size larger than 500 and smaller than 15 genes. For interpretation, a $p$ value of $<1 \%$ and a false discovery rate (FDR) $q$ value 
of $\leq 25 \%$ was considered significant. The Enrichment Scores (ES) were adjusted for variation in gene set size then represented by normalized enrichment scores (NES).

\section{Mouse studies.}

All studies were performed under an approved Institutional Animal Care and Use Committee (IACUC) protocol. Mouse epithelial ovarian cancer expressing luciferase (ID8-luc) were generated in the lab as previously described ${ }^{32}$. ID8-luc were cultured in in Dulbecco Modified 345 Eagle Medium (DMEM) media containing heat inactivated 5\% FBS (Atlas Biologicals Cat \# F-0500-D, 346 Lot F31E18D1) and grown under standard conditions. 6-8 week old female C57BL/6J mice and NSG (NOD-scid) mice from The Jackson Laboratory (Bar Harbor, ME) were injected intraperitoneally with 5x106 ID8-luc cells. Once engrafted, mice were randomized into treatment groups.

Hyperthermia and chemotherapy administration.

To apply heat, mice were anesthetized with isoflurane for immobilization. Mice then received an intraperitoneal injection of either PBS (vehicle) or cisplatin (1, $3 \mathrm{mg} / \mathrm{kg})$. Hyperthermia was delivered using the FDA- approved BSD500 instrument (Pyrexar). The peritoneal cavity was heated to $40^{\circ} \mathrm{C}$ for 20 minutes using a single microwave antenna (915 MHz) affixed under the abdominopelvic region of each mouse. Abdominal temperature was measured with individual thermistor sensors for each mouse. Mice were then placed prone on a circulating water bolus set at $40^{\circ} \mathrm{C}$ to optimize heating the abdominopelvic region specifically and to minimize the risk of thermal burn. Mice were monitored for signs of hyperventilation or stress.

\section{In vivo imaging.}

Two weeks after cell inoculation, mice were injected with D-luciferin intraperitoneally (Goldbio LUCK$1 \mathrm{G}, 150 \mathrm{mg} / \mathrm{kg}$ in $200 \mathrm{~mL}$ ) and anesthetized with inhaled isoflurane. After 5 minutes, mice were placed in IVIS Lumina (PerkinElmer) system to obtain bioluminescence images. The analysis of the images was done using Living Image Software, and the intensity of the signal (total flux) was recorded. This process was repeated weekly until endpoint.

Ethical approval and specimen collection- This study was approved by the Institutional Review Board (IRB) of Cleveland Clinic. Five female patients with high grade serous carcinoma were recruited and consented (Median age of 64) (Table 1). Tumor specimen was harvested at the time of interval 
debulking surgery and immediately after HIPEC administration (90 minutes). Specimens were obtained from the same site (omentum) to ensure for similar tumor microenvironment.

Tumor Dissociation- A total of ten tumor specimens were dissociated into a single cell suspension using a Papain Dissociation System (The Worthington Papain Dissociation System, kit\# LK003153) according to the manufacturer's protocol. A single cell suspension of each sample is then stored frozen at $-80 \mathrm{C}$. Prior to sc-RNA sequencing, dissociated samples were thawed in $37 \mathrm{C}$ (water bath), centrifuged, and suspended in 10\% FBS containing DMEM media.

Single cell RNA-sequencing analysis- scRNA-seq libraries were generated utilizing the Chromium Single Cell 3' V3 Kit (10X genomics) according to manufacture instruction. Following library preparation, sequencing was performed using Illumina (NovaSeq6000), and the raw data generated was aligned to GRCh38-3.0.0 using CellRanger 3.1.0. Sequencing depth and cellranger outputs were recorded and included (supplemental table 1). Post data alignment Seurat Version 4 in R version 4.0.1 was used for all downstream analysis and data integration. For each cell, the percentage of mitochondrial and ribosomal genes were calculated and then SCTtransform function was utilized to normalize the data and regress out the percent mitochondrial and percent ribosomal genes. Next, cells with more than 6000 features of RNA and less then 300 features of RNA were removed along with those cells which had greater than 30 percent mitochondrial gene content. Post removal of debris, Ribosomal, and Mitochondiral genes were removed prior to normalization with Seurat SCTransform normalization and rpca reduction. Using SCT counts a UMAP was then generated for all samples with overlapping identities based on biological differences. Clusters were subsequently manually identified using top markers of previously published datasets on single cell ovarian cancer ${ }^{33}$ additionally top markers of cell populations were used along ${ }^{34}$ with expert immunologist verification of population identify using known gene expression of Myeloid, T-cell, and Epithelial cell markers and their expression or lack of expression on clusters (Supplemental figure 3). When more than one population was present with no obvious or known identifiers, which would constitute this population as a subset, these populations were generically termed with ana underscore and a unique number. The abundance of each population 
was recorded as a percentage of total cells in the sample and then compared in the overall pre vs post analysis. These studies used a paired T-Test with Wilcoxon identifying no significant differences in the abundance of cell populations. Density and Joint Density is graphed using Nebulosa R package and volcano plots produced using EnhancedVolcano R package.

Gene and Pathway Enrichment Analysis-Differential gene expression was performed using Seurat comparing all pre-treatment $(n=5)$ vs all post-treatment $(n=5)$ samples with the raw RNA counts with a log fold change threshold of 1 . For sub analyses, the data was subset based on cell identity of interest and then compared pre-treatment vs post-treatment for all samples. Output from this differential expression analysis was then used for Volcano plots using (Enhanced Volcano version 3.11 in $\mathrm{R}$ version 4.0). The data output from differential gene expression were then used for Gene Set Enrichment Analysis (GSEA) with the c7.al.v7.1 Hallmark geneset. GSEA was performed by clusterProfiler version 3.11 with the differential gene expression list ordered by adjusted $P$ values and Average Fold Change prior to input and a cutoff $p$-value of 1. NES and $-\log 10 p$ value were then graphed to represent the pathways that are increased post treatment (Red) and those pathways that were higher pre-treatment (Blue).

Flow Cytometry Upon murine necropsy, single cell dissociated tumor samples were stored in freeze media (10\% DMSO in FBS, Atlas Biologicals) at -80C. All single cells suspensions were thawed on ice, washed once with 2\%BSA in PBS and stained with live/dead Blue Viability dye (Invitrogen) and then blocked in FACS buffer (PBS, 2\% BSA) containing FcR blocking reagent at 1:50 (Miltenyi Biotec) for 15 minutes. Subsequently, cells were incubated with antibodies at 1:100 dilution for 20 minutes before being washed and suspended in FACS buffer for analysis.

Cell populations were analyzed using a Cytek TM Aurora (CytekBio), and following un-mixing, populations were separated and quantified using FlowJo software (Tree Star Inc.). Gating methods for myeloid and lymphoid populations were performed following standardized gating strategies previously described ${ }^{35}, 36$. For a complete gating strategy please see Supplemental Figure 8. 
Data Availability- Raw fastq files will be deposited in GEO along with the individual cell count matrix of the dataset. In addition, the Seurat Object post data integration including SCT counts will be deposited with cell identities as they are described in this publication. 


\section{References.}

1. Torre LA, Trabert B, DeSantis CE, Miller KD, Samimi G, Runowicz CD, Gaudet MM, Jemal A and Siegel RL. Ovarian cancer statistics, 2018. CA Cancer J Clin. 2018;68:284-296.

2. Armstrong DK, Alvarez RD, Bakkum-Gamez JN, Barroilhet L, Behbakht K, Berchuck A, Berek JS, Chen LM, Cristea M, DeRosa M, ElNaggar AC, Gershenson DM, Gray HJ, Hakam A, Jain A, Johnston C, Leath CA, III, Liu J, Mahdi H, Matei D, McHale M, McLean K, O'Malley DM, Penson RT, Percac-Lima S, Ratner E, Remmenga SW, Sabbatini P, Werner TL, Zsiros E, Burns JL and Engh AM. NCCN Guidelines Insights: Ovarian Cancer, Version 1.2019. J Natl Compr Canc Netw. 2019;17:896-909.

3. Armstrong DK, Bundy B, Wenzel L, Huang HQ, Baergen R, Lele S, Copeland $\mathrm{L}$, Walker JL, Burger RA and Gynecologic Oncology G. Intraperitoneal cisplatin and paclitaxel in ovarian cancer. N Engl J Med. 2006;354:3443.

4. van Driel WJ, Koole SN, Sikorska K, Schagen van Leeuwen JH, Schreuder HWR, Hermans RHM, de Hingh I, van der Velden J, Arts HJ, Massuger L, Aalbers AGJ, Verwaal VJ, Kieffer JM, Van de Vijver KK, van Tinteren H, Aaronson NK and Sonke GS. Hyperthermic Intraperitoneal Chemotherapy in Ovarian Cancer. N Engl J Med. 2018;378:230-240.

5. Spiliotis J, Halkia E, Lianos E, Kalantzi N, Grivas A, Efstathiou E and Giassas S. Cytoreductive surgery and HIPEC in recurrent epithelial ovarian cancer: a prospective randomized phase III study. Ann Surg Oncol. 2015;22:1570-5.

6. Hatakeyama H, Wu SY, Lyons YA, Pradeep S, Wang W, Huang Q, Court KA, Liu T, Nie S, Rodriguez-Aguayo C, Shen F, Huang Y, Hisamatsu T, Mitamura T, Jennings N, Shim J, Dorniak PL, Mangala LS, Petrillo M, Petyuk VA, Schepmoes AA, Shukla AK, Torres-Lugo M, Lee JS, Rodland KD, Fagotti A, Lopez-Berestein G, Li C and Sood AK. Role of CTGF in Sensitivity to Hyperthermia in Ovarian and Uterine Cancers. Cell Rep. 2016;17:1621-1631.

7. Crestani A, Benoit L, Touboul C and Pasquier J. Hyperthermic intraperitoneal chemotherapy (HIPEC): Should we look closer at the microenvironment? Gynecol Oncol. 2020;159:285-294.

8. O'Sullivan D, Stanczak MA, Villa M, Uhl FM, Corrado M, Klein Geltink RI, Sanin DE, Apostolova P, Rana N, Edwards-Hicks J, Grzes KM, Kabat AM, Kyle RL, Fabri M, Curtis JD, Buck MD, Patterson AE, Regina A, Field CS, Baixauli F, Puleston DJ, Pearce EJ, Zeiser R and Pearce EL. Fever supports CD8(+) effector T cell responses by promoting mitochondrial translation. Proc Natl Acad Sci U S A. 2021;118.

9. Bing C, Nofiele J, Staruch R, Ladouceur-Wodzak M, Chatzinoff Y, Ranjan A and Chopra R. Localised hyperthermia in rodent models using an MRI-compatible high-intensity focused ultrasound system. Int $J$ Hyperthermia. 2015;31:813-22.

10. Miailhe G, Arfi A, Mirshahi M, Eveno C, Pocard M and Touboul C. A new animal model for hyperthermic intraperitoneal chemotherapy (HIPEC) in tumor-bearing mice in the treatment of peritoneal carcinomatosis of ovarian origin. J Visc Surg. 2018;155:183-189.

11. Hildebrandt B, Wust P, Ahlers O, Dieing A, Sreenivasa G, Kerner T, Felix R and Riess H. The cellular and molecular basis of hyperthermia. Crit Rev Oncol Hematol. 2002;43:33-56.

12. Issels RD. Hyperthermia adds to chemotherapy. Eur J Cancer. 2008;44:2546-54.

13. Gao F, Ye Y, Zhang Y and Yang J. Water bath hyperthermia reduces stemness of colon cancer cells. Clin Biochem. 2013;46:1747-50.

14. Doherty JA, Peres LC, Wang C, Way GP, Greene CS and Schildkraut JM. Challenges and Opportunities in Studying the Epidemiology of Ovarian Cancer Subtypes. Curr Epidemiol Rep. 2017;4:211-220.

15. Ozsolak F and Milos PM. RNA sequencing: advances, challenges and opportunities. Nat Rev Genet. 2011;12:87-98.

16. Picelli S. Single-cell RNA-sequencing: The future of genome biology is now. RNA Biol. 2017;14:637-650. 17. Horowitz MP, Alali Z, Alban T, Hong C, Esakov EL, Hwang TH, Lathia JD, Michener CM, DeBernardo R and Reizes O. Single-Cell Analysis of Hyperthermic Intraperitoneal Chemotherapy Treated Tumors Reveals Distinct Cellular and Molecular Responses. bioRxiv. 2020:2020.10.05.326710.

18. Winterhoff B, Talukdar S, Chang Z, Wang J and Starr TK. Single-cell sequencing in ovarian cancer: a new frontier in precision medicine. Curr Opin Obstet Gynecol. 2019;31:49-55. 
19. Stope MB, Koensgen D, Burchardt M, Concin N, Zygmunt M and Mustea A. Jump in the fire--heat shock proteins and their impact on ovarian cancer therapy. Crit Rev Oncol Hematol. 2016;97:152-6.

20. Frey B, Weiss EM, Rubner Y, Wunderlich R, Ott OJ, Sauer R, Fietkau R and Gaipl US. Old and new facts about hyperthermia-induced modulations of the immune system. Int J Hyperthermia. 2012;28:528-42.

21. Yum S, Li M and Chen ZJ. Old dogs, new trick: classic cancer therapies activate cGAS. Cell Res. 2020;30:639-648.

22. Hopfner KP and Hornung V. Molecular mechanisms and cellular functions of cGAS-STING signalling. Nat Rev Mol Cell Biol. 2020;21:501-521.

23. Motwani M, Pesiridis $S$ and Fitzgerald KA. DNA sensing by the cGAS-STING pathway in health and disease. Nat Rev Genet. 2019;20:657-674.

24. Neal JA, Sugiman-Marangos S, VanderVere-Carozza P, Wagner M, Turchi J, Lees-Miller SP, Junop MS and Meek K. Unraveling the complexities of DNA-dependent protein kinase autophosphorylation. Mol Cell Biol. 2014;34:2162-75.

25. Laird PW, Zijderveld A, Linders K, Rudnicki MA, Jaenisch R and Berns A. Simplified mammalian DNA isolation procedure. Nucleic Acids Res. 1991;19:4293.

26. Saygin C, Wiechert A, Rao VS, Alluri R, Connor E, Thiagarajan PS, Hale JS, Li Y, Chumakova A, Jarrar A, Parker Y, Lindner DJ, Nagaraj AB, Kim JJ, DiFeo A, Abdul-Karim FW, Michener C, Rose PG, DeBernardo R, Mahdi $\mathrm{H}$, McCrae KR, Lin F, Lathia JD and Reizes O. CD55 regulates self-renewal and cisplatin resistance in endometrioid tumors. J Exp Med. 2017;214:2715-2732.

27. Johnson N, Li YC, Walton ZE, Cheng KA, Li D, Rodig SJ, Moreau LA, Unitt C, Bronson RT, Thomas HD, Newell DR, D'Andrea AD, Curtin NJ, Wong KK and Shapiro GI. Compromised CDK1 activity sensitizes BRCAproficient cancers to PARP inhibition. Nat Med. 2011;17:875-82.

28. Kechin A, Boyarskikh U, Kel A and Filipenko M. cutPrimers: A New Tool for Accurate Cutting of Primers from Reads of Targeted Next Generation Sequencing. J Comput Biol. 2017;24:1138-1143.

29. Wagner GP, Kin K and Lynch VJ. Measurement of mRNA abundance using RNA-seq data: RPKM measure is inconsistent among samples. Theory Biosci. 2012;131:281-5.

30. Patro R, Duggal G, Love MI, Irizarry RA and Kingsford C. Salmon provides fast and bias-aware quantification of transcript expression. Nat Methods. 2017;14:417-419.

31. Love MI, Huber W and Anders S. Moderated estimation of fold change and dispersion for RNA-seq data with DESeq2. Genome Biol. 2014;15:550.

32. Chambers LM, Esakov E, Braley C, AlHilli M, Michener C and Reizes O. Use of Transabdominal Ultrasound for the detection of intra-peritoneal tumor engraftment and growth in mouse xenografts of epithelial ovarian cancer. PLoS One. 2020;15:e0228511.

33. Izar B, Tirosh I, Stover EH, Wakiro I, Cuoco MS, Alter I, Rodman C, Leeson R, Su MJ, Shah P, Iwanicki M, Walker SR, Kanodia A, Melms JC, Mei S, Lin JR, Porter CBM, Slyper M, Waldman J, Jerby-Arnon L, Ashenberg O, Brinker TJ, Mills C, Rogava M, Vigneau S, Sorger PK, Garraway LA, Konstantinopoulos PA, Liu JF, Matulonis U, Johnson BE, Rozenblatt-Rosen O, Rotem A and Regev A. A single-cell landscape of high-grade serous ovarian cancer. Nat Med. 2020;26:1271-1279.

34. Zhang AW, O'Flanagan C, Chavez EA, Lim JLP, Ceglia N, McPherson A, Wiens M, Walters P, Chan T, Hewitson B, Lai D, Mottok A, Sarkozy C, Chong L, Aoki T, Wang X, Weng AP, McAlpine JN, Aparicio S, Steidl C, Campbell KR and Shah SP. Probabilistic cell-type assignment of single-cell RNA-seq for tumor microenvironment profiling. Nat Methods. 2019;16:1007-1015.

35. Alban TJ, Alvarado AG, Sorensen MD, Bayik D, Volovetz J, Serbinowski E, Mulkearns-Hubert EE, Sinyuk M, Hale JS, Onzi GR, McGraw M, Huang P, Grabowski MM, Wathen CA, Ahluwalia MS, Radivoyevitch T, Kornblum HI, Kristensen BW, Vogelbaum MA and Lathia JD. Global immune fingerprinting in glioblastoma patient peripheral blood reveals immune-suppression signatures associated with prognosis. JCI Insight. 2018;3.

36. Bayik D, Zhou Y, Park C, Hong C, Vail D, Silver DJ, Lauko A, Roversi G, Watson DC, Lo A, Alban TJ, McGraw M, Sorensen M, Grabowski MM, Otvos B, Vogelbaum MA, Horbinski C, Kristensen BW, Khalil AM, Hwang TH, 
Ahluwalia MS, Cheng F and Lathia JD. Myeloid-Derived Suppressor Cell Subsets Drive Glioblastoma Growth in a Sex-Specific Manner. Cancer Discov. 2020;10:1210-1225. 
Figure Legends.

Fig. 1. Hyperthermic treatment increases DNA damage and with no effect on cell viability in response to cisplatin in chemo resistant epithelial ovarian cancer cells. $A$. $A 2780$ and $A 2780^{C P}$ were treated for 90 minutes with cisplatin at $42 \mathrm{C}$ or $37 \mathrm{C}$ followed by 72 hours incubation with cisplatin at $37 \mathrm{C}$. Representative data from an experiment that was repeated 3 times, $n=6$ replicates per condition. No statistical significance. B. Cisplatin adduct formation is induced in heat treated $\mathrm{A} 2780^{\mathrm{CP}}$ cells at 90 minutes compared to normothermic control cells. C. $\gamma \mathrm{H} 2 \mathrm{AX}$ expression analysis following 72 heat or normothermic treatment in vehicle (V37, V42) and cisplatin (C37, C42) treated $A 2780^{\mathrm{CP}}$ and ID8 EOC. Representative immunoblot from an experiment repeated 3 times. Tubulin and Cyclophilin $B$ used as loading control. D. $\gamma \mathrm{H} 2 \mathrm{AX}$ foci formation at 72 hours in $\mathrm{A} 2780^{\mathrm{CP}}$ EOC cells treated at $42 \mathrm{C}$ or $37 \mathrm{C}$ for 90 minutes in presence of vehicle (V37, V42) or cisplatin $(\mathrm{C} 37, \mathrm{C} 42)$ and foci quantified based on fluorescence/cell. Experiment was repeated at least 3 times. V42 is significantly different from all other groups $\left({ }^{*} p<0.0001\right)$. F. Volcano plot at 90 minutes comparing $42 \mathrm{C}$ plus cisplatin to $37 \mathrm{C}$ plus cisplatin in A2780 ${ }^{\mathrm{CP}}$ cells. G. Volcano plot at 72 hours comparing $42 \mathrm{C}$ plus heat to $37 \mathrm{C}$ plus heat in A2780 ${ }^{\mathrm{CP}}$ cells. H. Gene Set Enrichment analysis of RNAseq identifies heat shock and TNF $\alpha$ pathways.

Fig. 2. Single Cell RNAseq analysis of pre- and post-HIPEC treated specimen identifies heat shock responsive immune cells. A. Schematic representation of the flow of tissues collection and processing for single cell RNA sequencing. A tumor specimen is taken immediately before and after HIPEC administration (90 minutes) at the time of interval debulking surgery. specimens are obtained from the same site (omentum) in order to reduce variability. Tumor samples are dissociated into a single cell suspension and followed by scRNA-seq to identify cell types and gene expression profile. B. UMAP representing $n=10$ samples from $n=5$ patients with 2 timepoints each, showing the general celltype classifications B. C. Differential gene expression comparing Post-Treatment and Pre-Treatment samples $n=5$ for each group. D. Hallmark pathway analysis using GSEA (gene set enrichment anlaysis) and the HALLMARK genesets based of the differential expression analysis of post vs pre-treatment samples overall. E. Pathway analysis of the Gene Ontology biological process Response to Heat pwathway gene set $n=161$ genes analyzed ans scored for each cell from all $n=5$ samples pre-treatment and $n=5$ samples post-treatment. F UMAP representing the unsupervised clustering analysis of all $n=10$ sampels with detailed naming based on gene expression. $G$ comparison of the overall percentages of each cell type present for all pre $n=5$ and all post $n=5$ treatment samples.

Fig. 3. A. Heat shock pathway was scored for each individual cell for the $n=5$ samples pre-treatment and $n=5$ samples post treatment and graphed via violin plots for distribution across all cell types identified. B. UMAP representation of the sample cells pre and post treatment, colored by their expression level of the GO biological process response to heat pathway. C. Differential expression analysis of the $n=5$ pre and $n=5$ post treatment CD8+ Tcell HSP+ cell subset. D. Density plot representing the distribution of cells expressing the $\mathrm{GO}$ biological process response to heat pathway. Hallmark pathway analysis from the differential gene expression of HSP+ CD8 T cells post vs pretreatment graphed as NES score on the $x$-axis and colored by the $p$-value with red showing $p<0.05$. F$\mathrm{H}$. Density plots of TNF alpha expression, interferon gamma expression, and CGAS expression across all $n=10$ samples pre and post-treatment. Violin plot demonstrating the distribution of CGAS expression in the CD8 T cells HSP+ population pre vs. post-treatment. J. Joint Density plots of CGAS and Heat shock response pathway across all $n=10$ samples pre and post-treatment.

Fig. 4. cGAS inflammatory pathway is induced in dendritic cells of HIPEC specimen. A. Representative UMAP showing the cells that were selected for sub-setting the Dendritic Cell population defined by it's heat shock positive protein signature. Differential expression analysis of the $n=5$ pre and $\mathrm{n}=5$ post treatment Dendritic Cells HSP+ cell subset. Hallmark pathway analysis from the differential 
gene expression of HSP+ Dendritic cells post vs pre-treatment graphed as NES score on the $\mathrm{x}$-axis and colored by the $p$-value with red showing $p<0.05$. D. Violin plot of CGAS expression and HLA expression between the pre and post treatment cells from the DC HSP+ cell population. Wilcoxon with multiple comparisons Bonferroni correction were performed for $\mathrm{D}, \mathrm{E}$ comparisons.

Figure 5. Treatment of mouse epithelial ovarian cancer with heated cisplatin leads to increased efficacy in immune competent but not in immune deficient mice. A. Detailed schematic of animal HIPEC protocol. ID8-luc, a EOC mouse line, is inoculated into immune competent C57BL/6 or immune deficient NSG mice intraperitoneally. Tumor establishment and growth is confirmed using In Vivo Imaging System (IVIS) optical spectrum. Cisplatin $(5 \mathrm{mg} / \mathrm{kg})$ is injected and superficial hyperthermia of $40^{\circ} \mathrm{C}$ is applied using an FDA approved hyperthermia unit (BSD500) for 20 minutes. IVIS assessment is performed weekly thereafter to monitor tumor size and growth following the treatment. B. Effect of hyperthermic cisplatin treatment of murine EOC model in immune competent mice. Tumor bearing C57BI/6J mice are treated for 20 minutes with no heat plus vehicle (V37), abdominal heat plus vehicle (V40), no heat plus varying concentrations of cisplatin $(0.5 \mathrm{mg} / \mathrm{kg}, 5 \mathrm{mg} / \mathrm{kg})(\mathrm{C} 37)$, and heat plus varying concentrations of cisplatin (C40). Change in tumor growth relative to normothermic controls is shown. Representative data from an experiment that replicated 3 times. $\left(n=4 /\right.$ condition, $\left.{ }^{*} p<0.05\right)$. C. Effect of hyperthermic cisplatin treatment of murine EOC model in immune deficient mice. Tumor bearing NSG mice are treated for 20 minutes with no heat plus vehicle (V37), abdominal heat plus vehicle (V40), no heat plus varying concentrations of cisplatin $(0.5 \mathrm{mg} / \mathrm{kg}, 5 \mathrm{mg} / \mathrm{kg})(\mathrm{C} 37)$, and heat plus varying concentrations of cisplatin (C40). Change in tumor growth relative to normothermic controls is shown. Therapeutic response remains unchanged in hyperthermic versus normothermic cisplatin treated mice. Dose dependent suppression of tumor growth in response to cisplatin therapy is observed (cisplatin dose $0 \mathrm{mg} / \mathrm{kg}, 1 \mathrm{mg} / \mathrm{kg}, 3 \mathrm{mg} / \mathrm{kg}, 5 \mathrm{mg} / \mathrm{kg}$ ) with no impact of heat on efficacy in absence of immune system. Representative findings from a study that was repeated 2 times. $(n=5, p<0.05)$. 


\section{Supplemental Figures Legends.}

Supplemental Fig. 1. Heat in presence of cisplatin modestly sensitizes human and mouse epithelial ovarian cancer cells to cisplatin. Cisplatin IC50 curves for OV81 (A), OV81 ${ }^{\mathrm{CP}}$ (B), and ID8 (C), ID8 VEGF (D). cells in the presence and absence of heat. (E) Representative heat maps of GSEA of C42 and C37 CP70 cells at 90 minutes. Enriched gene sets in C42 over C37 treated CP70 cells post 90 minutes $(F)$, and 72 hours $(G)$. (NOM p-value $<0.01$, FDR q-value $<0.25$ ).

Supplemental Fig. 2. The impact of heat is enriched at 90 minutes followed by an increased impact of cisplatin following $\mathbf{7 2}$ hours of culture. Volcano plots denoting leading edge genes at V42 over V37 at 90 minutes (A) and 72 hours (B). Enriched gene sets (C) and plots (D) in V42 over V37 treated $A 2780^{C P}$ cells post 90 minutes and at 72 hours $(E)$. Volcano plots denoting leading edge genes at C42 over V42 at 90 minutes $(F)$ and 72 hours $(G)$. Enriched gene sets $(H)$ in C42 over V42 treated CP70 cells post 90 minutes and at 72 hours (I and J). (NOM p-value $<0.01$, FWER q-value $<0.20$ ).

Supplemental Fig. 3. Violin plot representation of the gene expression of common markers for T cell populations used to identify $T$ cell subsets, graphed across the lymphocyte populations only.

Supplemental Fig. 4. Violin plot representation of the gene expression of common markers for myeloid populations used to identify myeloid subsets, graphed across the myeloid populations only.

Supplemental Fig. 5. A. Top 10 positively, differentially expressed, genes per cluster as compared to all other clusters are graphed as a heatmap for all 29 cell types. Analysis of the relative percent of each cell type per sample with paired samples connected by lines and statistics shown for paired T-test analysis.

Supplemental Fig. 6. Pathway analysis of the GO biological process response to heat pathway of $\mathrm{n}=161$ genes was performed on all cells from the single cell RNA-seq dataset and then the average of this signature was identified for each cell type per sample. Comparing pre vs post treatment in boxplots with data points, each paired sample is connected by a line. Paired T-test statistics are added to the top of each graph for their comparison.

Supplemental Fig. 7. A. Cell cycle scoring was performed via Seurat V4 and cells were then colored by their estimated cell cycle stage (G1, S, G2M). B. Violin plot of CGAS expression across all cell types from the $n=10$ samples including all cells.

Supplemental Fig. 8. Gating strategy for immune analysis of tumors and impact of HIPEC on myeloid populations. A. Multi-parameter gating strategy for myeloid and lymphoid cell populations in ID8 tumors. B. 24 hours following HIPEC therapy no significant differences were observed between treatment groups. C. 2 weeks following HIPEC therapy macrophages were increased in ID8 tumors treated with cisplatin and heat $(\mathrm{C} 40)$ compared to heat alone $(\mathrm{V} 40) . n=4-5$ mice per group ${ }^{* *} p<0.01$, FDR T Test 


\section{Supplementary Files}

This is a list of supplementary files associated with this preprint. Click to download.

- SupplementalFiguresHIPECJune202021.pdf 